\title{
Fiscal Reaction Rules in Numerical Macro Models
}

\author{
Richard Johnson
}

February 2001

\section{RWP 01-01}

Research Division

Federal Reserve Bank of Kansas City

Richard Johnson is an economist at the Federal Reserve Bank of Kansas City. This paper was largely written while the author was working in the Fiscal Policies Division of the European Central Bank. The author would like to thank the IMF's Douglas Laxton, Peter Isard, Hamid Faruqee, Eswar Prasad, and Bart Turtelboom for making their MULTIMOD Mark III model available at www.imf.org/external/np/res/mmod/mark3/index.htm, and for their comments on this paper. The views expressed herein are solely those of the author and do not reflect those of the Federal Reserve Bank of Kansas City or the Federal Reserve System.

Johnson email: richard.johnson@kc.frb.org. 


\begin{abstract}
To avoid exploding government debt, numerical macro models require 'fiscal reaction rules'. Present rules impose arbitrary, backward-looking reaction of taxes to deviations of the debt ratio from a target. Arbitrary models may be poor guides to monetary policy. An optimising fiscal policy-maker would look forward, and maximise an objective function. A simple optimising model implies the future tax rate should be constant. I implement the constant-future-tax rule in the IMF's MULTIMOD model. Simulations show model outcomes' sensitivity to the choice of fiscal rule. A constant tax rate induces smoother and hence preferable consumption paths to MULTIMOD's existing rule.
\end{abstract}

JEL Classification: $\quad$ C63, E17, E62, H21, H63

Key words: Computational techniques, forecasting and simulation, fiscal policy, optimal taxation, government debt 


\section{Introduction}

Macroeconomic modellers must choose monetary and fiscal reaction rules. The fiscal rule must make government taxes or spending a function of government debt, or else debt will be free to explode. Fiscal reaction rules in central bank models prevent debt explosion in arbitrary ways. These models' simulation results are therefore somewhat arbitrary. Since they make fiscal authorities look only backwards, and fix the long-run debt ratio regardless of shocks, these rules cannot be considered optimal in any model. Model users may prefer empirically plausible fiscal assumptions to optimal ones. ${ }^{1}$ Yet there is little empirical justification for present fiscal reaction rules either. I compare simulated response to a shock under a standard, arbitrary fiscal rule to those under the constant tax-rate rule, using the IMF's

MULTIMOD model. Constant tax rates are optimal in the Ramsey consumption model. The results show that fiscal rules drive model outcomes, and that the constanttax rule can produce preferable paths of private consumption to an arbitrary rule. I conclude that fiscal rules should be chosen more thoughtfully, and optimality violated only with justification. Exploration of the 'fiscal rule problem' could inform policy debates. For while many commentators have a strong understanding of fiscal rules such as the balanced budget or the Maastricht criteria, ${ }^{2}$ few have a strong sense of which fiscal rule is optimal.

Research on optimal fiscal policy through time was stimulated by Barro's $(1979,1995)$ result that a constant tax rate is optimal in a Ramsey consumption model. ${ }^{3}$ Zhu (1992) adds labour supply to the Ramsey model and finds constant tax rates optimal only for some assumptions about consumer preferences. Zhu and Chari and Kehoe (1999) introduce stochastic shocks to the Ramsey model and show that optimal tax rates do not follow a random walk, as had been conjectured. Literature on fiscal rules in computer macro models has taken little from this theoretical literature. Masson, Symansky and Meredith (1990) assert that fiscal rules should make the debt ratio "return to its control solution over the horizon typically used for model simulations." Though this condition has no economic rationale, most central bank models' fiscal rules do fix the long run debt ratio exogenously. Mitchell et. al. (2000) compare fiscal rules from several macro models, and note that the long-run debt ratio could be endogenous to the history of shocks. They conclude that, since fiscal rules drive simulation results, they should be made uniform to permit comparison of other model features. However, the question of what the fiscal rule should be remains. I believe this paper is the first to implement a fiscal rule, optimal at least in some analytical model, in a central bank's numerical macro model. ${ }^{4}$

I use a search algorithm to find the constant tax rate consistent with a stable government debt ratio in the long run. Two interesting economic points became apparent in writing this algorithm. First, computer macro models typically require the long-run debt-GDP ratio be specified before any shocks are imposed. My algorithm

\footnotetext{
${ }^{1}$ I am grateful to Andrew Levin for emphasizing the distinction between positive and normative modelling.

2 The Maastricht criteria are debt-GDP ratios below 0.6 and nominal deficit-GDP ratios below 0.03 .

3 Barro's better-known (1979) derivation that constant tax rates are optimal assumes, uncomfortably, that output and interest rates are invariant to tax rates.

${ }^{4}$ Both Zhu (1992) and Chari and Kehoe (1999) implement optimal rules in numerical versions of perfect-market Ramsey models.
} 
'frees' the long-run debt ratio by searching for the constant tax rate $\tau^{*}$ that makes the debt ratio stable at some level $b^{*}$ in the long run. This algorithm takes into account the history of economic shocks and the structure of the model, so $\tau^{*}$ and $b^{*}$ are endogenous to them. Freeing the long-run debt ratio is analogous to Kozicki and Tinsley's (2001) use of 'moving endpoints' to remove the restrictive modelling assumption that 'the market believes the long-run policy goal for inflation has not and will not change over time'.

A second economic lesson emerged from the problem of making MULTIMOD solve. No constant tax rate can make the debt ratio precisely stable by a finite end-period. Therefore, although we 'shoot' at stability with different choices of constant $\tau$, necessarily we miss, so the model generally fails to converge. My solution is to retain a standard fiscal reaction rule but turns it on only after, say, thirty years of each simulation. The tax rate then jumps either up or down in year thirty. The combination $\left(\tau^{*}, b^{*}\right)$ minimizes the tax-rate change in this year. The small tax-rate 'wobble' remaining at this 'switch-on' date has a negligible effect on the simulation results. ${ }^{5}$ From this I conclude that, although computational tricks may be necessary to solve the model, happily these need not materially affect its economic properties. ${ }^{6}$

I simulate an economy with the constant tax rule given government spending and money supply shocks in the IMF's MULTIMOD Mark III model. I compare the results to those using the standard reaction rule written by MULTIMOD's developers. This is a fairly general comparison between the constant-tax rule and one imposing more tax-rate volatility. The constant-tax rule typically implies a smoother path of GDP and a different long-run level. Therefore this rule implies monetary shocks affect real variables in the long run. From the perspective of optimal fiscal policy, we see that the superfluous volatility of taxes under the standard rule creates superfluous volatility in private consumption. I calculate 'aggregate utility' from the induced time-paths of consumption using an iso-elastic utility function. 'Aggregate utility' is higher under the constant tax rule than under MULTIMOD's existing rule for a range of discount rates and elasticities of inter-temporal substitution. I suspect this lower volatility would make the consumption-paths under the constant-tax rule preferable to those induced by any of the fiscal rules currently used in central bank models.

This paper proceeds as follows. Section 2 explains the need for fiscal reaction rules. Section 3 repeats Barro's (1995) derivation of the constant-tax rule from an optimal consumption model. It then discusses further results from optimal fiscal policy literature. Section 4 describes present fiscal rules in several working macroeconomic models. Section 5 illustrates the sensitivity of models' performance to the fiscal rule chosen. Section 6 describes the MULTIMOD model, and explains my method of implementing a constant tax rate. It then compares the simulation performance of the constant-tax rule with MULTIMOD's existing rule for government spending and monetary shocks. Section 7 concludes that the justification for the fiscal rule chosen should be thoughtful and explicit given the variety of possible rules and the sensitivity of model outcomes to them.

\footnotetext{
${ }^{5}$ The choice of 'switch-on date' also has little effect on the results, provided it is far from the simulation's start.

${ }^{6}$ See Anderson (2000) for a 'shooting' algorithm finding optimal behaviour within a given model. My algorithm imposes behaviour optimal in a different model than that in which I employ it.
} 


\section{The Need for a Fiscal Reaction Rule}

In this section I assume monetary authority keeps the price level constant. I thus assume the monetary authority does not monetize government debt. While interaction between fiscal and monetary policy may be important, I wish here to concentrate on the role of fiscal rules. With fixed prices real government debt $B$ evolves as:

$$
\dot{B}=r B+G-T
$$

where $G$ denotes government spending and $T$ tax revenues. If the path of government spending is given exogenously, equation (1) integrates to

$$
\int_{0}^{\infty} \tau(s) Y(s) e^{-\int_{0}^{s} r(u) \cdot d u} \cdot d s-B_{0}-\int_{0}^{\infty} G(s) e^{-\int_{0}^{s} r(u) \cdot d u} \cdot d s=\lim _{s \rightarrow \infty} B_{s} e^{-\int_{0}^{s} r(u) \cdot d u}
$$

where $s$ indexes times, $B_{0}$ is the government debt at time zero, $Y(s)$ is aggregate income at time $s$, tax revenue $T=\tau(s) Y(s)$, and $\tau(s)$ is the tax rate at time $s$. The righthand side of (2) is the limiting net present value of government debt. Consumers will not lend to the government by buying bonds unless they are repaid in net present value. Therefore governments wishing to sell bonds must adopt a path of tax rates making this limit zero. Assume the government adopts such a tax-rate path $\tau_{l}$. Now suppose a shock raises initial debt from $B_{0}$ to $B_{0}$ '. From (1), without a change in the path of revenues or spending, the additional debt will grow at rate $r$. With unchanged tax rates, the right-hand side of (2) will not be zero and consumers will expect a debt default. Thus the government needs a 'fiscal reaction rule' for changing the path of tax rates $\tau_{1}$ to some new path $\tau_{2}$ to prevent debt exploding. No such reaction rule would be needed were there no economic shocks or all shocks offset each other perfectly. Either case is possible but has a probability of zero.

Since rational consumers will not buy debt that will not be repaid, we might feel that consumer optimisation implies a fiscal reaction rule without our assuming one. In the Barro-Ramsey model, consumer optimisation implies the government obeys its budget constraint, so we need not assume this separately. ${ }^{7}$ However, this does not establish what path of taxes the government will choose, since many paths will satisfy the constraint. Fiscal rules would be proven unnecessary if they could be safely deleted from macro models. Figure 1 demonstrates what would go wrong in this case. It shows the simulated path of the German government debt-GNP ratio in an experiment with MULTIMOD Mark III. German government consumption was increased by 0.5 percent of GDP in 2010 only, and thereafter returned to its baseline. MULTIMOD Mark III has the fiscal reaction rule

$\tau_{s}=\tau_{X}(1-\alpha)+\alpha\left(\sum_{i=s-2}^{i=s+2} \tau_{i}+\delta\left(\frac{B_{s-1}}{Y_{s-1}}-\left(\frac{B}{Y}\right)^{*}\right)\right)$

\footnotetext{
${ }^{7}$ I am grateful to Fabrice Orlandi for emphasizing this point.
} 
where $\tau_{s}$ is the tax rate at time $s, \tau_{X}$ is an exogenous tax rate, $Y$ is GNP, $(B / Y)^{*}$ is a target debt ratio, and $\alpha$ and $\delta$ are parameters. The crucial feature of rule (3) is that it forces tax rates to rise if debt grows too high. In the experiment depicted in figure 1 this reaction feature is 'switched off' by setting $\alpha=0$ from 2010 to 2039, and thereafter 'switched on' again by setting $\alpha=1$. Figure 1 shows that, after the initial increase in the debt ratio in 2010 due to higher government spending that year, the debt ratio continues to rise as accumulated debt is rolled over. The tax rate is constrained not to adjust upwards until 2040, and before then there appears to be no other mechanism to bring the debt ratio back to its target. After 2040, the 'switched on' reaction rule increases the tax rate and brings the debt ratio back to its baseline value. Arguing that fiscal reaction rules are unnecessary would require presenting figures analogous to figure 1 showing that debt stabilises without a fiscal rule. I posit that with probability one this will not occur.

\section{Theories of Optimal Fiscal Policy through Time}

This section reprises Barro's (1995) proof that constant consumption taxes are optimal in a Ramsey consumption model with certainty. Consumers desire smooth consumption, and constant tax rates permit this. I then discuss literature on optimal fiscal policy in Ramsey models including labour supply and stochastic shocks. Central bank macro models are based on 'overlapping generations' or finite-lifetime assumptions, rather than the Ramsey model's infinite lifetimes. I therefore discuss why existing fiscal rules are unlikely to be optimal in any model, whatever its assumptions. Finally I discuss the constraint that fiscal policy remain fixed for some finite period after a shock.

\section{Fiscal Policy in a Ramsey Consumption Model}

Suppose consumers gain utility from consumption, but not from government spending, and discount at the rate $\rho$. I assume no new consumers enter the economy after the initial period. Each consumer's utility is

$$
\int_{0}^{\infty} u(c) e^{-\rho s} \cdot d s
$$

I assume consumers only have capital. Initial private assets $A_{0}=K_{0}+B_{0}$, where $K$ is capital and $B$ government debt. The government cannot use lump-sum taxes, but instead must raise revenues through taxes on consumption $\tau(s)$. The consumer's maximisation problem is thus

$$
\max \int_{0}^{\infty} u(c) e^{-\rho s} . d s \quad \text { s.t. } \quad \dot{A}=r A-c(1+\tau), \quad A_{0}>0, \quad \lim _{s \rightarrow \infty} A_{s} e^{-\int_{0}^{s} r(u) \cdot d u}=0
$$

where a dot over a variable denotes its time derivative. The government must finance its spending and initial debt through consumption taxes. Its budget constraint is thus 


$$
\int_{0}^{\infty} \tau(s) c(s) e^{-\int_{0}^{s} r(u) \cdot d u} \cdot d s=B_{0}+\int_{0}^{\infty} G(s) e^{-\int_{0}^{s} r(u) \cdot d u} \cdot d s
$$

Since government debt is part of private assets, the consumers' optimization condition $\lim _{s \rightarrow \infty} A_{s} e^{-\int_{0}^{s} r(u) \cdot d u}=0$ implies $\lim _{s \rightarrow \infty} B_{s} e^{-\int_{0}^{s} r(u) \cdot d u}=0$. The consumer solves his problem using the Euler first-order condition

$$
-\frac{u^{\prime \prime}(c) \dot{c}}{u^{\prime}(c)}=r-\rho-\frac{\dot{\tau}}{1+\tau}
$$

A benevolent government would set the path of tax rates $\tau(s)$ to allow the maximum consumer utility, while raising its required revenue. The last term in (7) represents a distortion created by government tax policy. All distortion can be removed by setting $\dot{\tau}=0$, implying a constant tax rate. The level of the tax rate is then determined by the constraint (6). Assuming $u^{\prime}(c)>0$ and $u^{\prime \prime}(c)<0$, consumers desire smooth consumption, and the constant consumption tax allows it.

\section{Stochastic Shocks, Labour Supply and Money in the Ramsey Model}

Zhu (1992) analyses a Ramsey model with private consumption and laboursupply decisions and shocks both to productivity and government spending. Zhu finds that, for certain classes of utility function only, constant consumption and labour taxes are optimal. For these assumptions optimal reaction to shocks consists of changes in the consumption tax rate, or, equivalently, state-contingent capital taxes. Since taxes on labour create economic distortion, optimising governments would like to levy 'surprise' 100 percent taxes on existing capital. Therefore the government would need credibly to commit not to levy such taxes to support the optimum in which such taxes are neither expected nor occur.

Chari and Kehoe (1999) add money to the stochastic Ramsey model and show that, since inflation taxes nominal debt, state-contingent inflation is equivalent to state-contingent taxation of capital. They also find that optimal tax rates in an environment with economic shocks do not follow a random walk, as Barro (1979) had conjectured. Given this finding, my imposition of a one-off change in tax rates after a shock cannot be considered optimal in a stochastic model. However, central bank models typically assume certainty, since from a simulation's start, agents know all future variables. Constant tax rates are optimal at least in the simple certainty model described above.

\section{Optimal Taxation in Overlapping-Generations Models}

Central bank models typically assume 'overlapping generations' of consumers rather than the indefinitely-living dynasties of the Ramsey model. While fiscal policy optimal in the Ramsey model may not be optimal in overlapping-generations models, this does not justify existing arbitrary fiscal rules. In no model will an optimising fiscal agency only look backwards. Further, the constraint that government debt 
return to a pre-specified level is simply not necessary. If we add a constraint to a maximization exercise, the value of the optimum attained will be worse than that attained without it, or equal if the constraint is not binding. Thus, in general we would not expect optimal fiscal policy in any model to obey this additional constraint.

\section{'Stickiness' in Tax Rates}

Besides the physical costs of printing new forms, there may be psychic costs of agents' learning new tax rates and for politicians in deciding them. These costs might introduce some 'stickiness' in the tax rate. The current method of modelling a 'sticky' tax rate is to use a backward-looking reaction rule but turn it off for the first $\mathrm{T}$ years of every simulation. ${ }^{8}$ After T years tax feedback is turned back on and generally forces the debt ratio back to its initial value. Thus behaviour after year $\mathrm{T}$ is hard to justify. Below I assume a forward-looking government unable to react until date $\mathrm{T}$ would set a constant tax rate from then on. A comparison between backward and forward-looking 'sticky-tax' rules shows quite how unnecessary is the volatility of taxes under current reaction rules. Part of this volatility is due to the stipulation that the debt ratio must eventually return to its initial value, while $\mathrm{T}$ years after a shock the debt ratio may be far above or below this value.

\section{Fiscal Reaction Rules in Current Use}

This section summarizes existing literature on fiscal rules in macro models by listing several in current use. This literature has two themes. The first, as in Coletti et. al. (1996), is that macro models require fiscal reaction rules. The second, evident in Mitchell et. al. (2000), is that many fiscal rules are possible and that the choice of rule profoundly affects models' performance. In contrast to the extensive literature on monetary policy rules, ${ }^{9}$ there has been little discussion of which fiscal rule modellers should choose. In related work, Auerbach and Kotlikoff ${ }^{10}$ have studied tax reforms in numerical macro models without money. The rules described here, including Auerbach and Kotlikoff's, all impose arbitrary feedback from debt to taxes or spending. This arbitrariness is evident in the fact that all the rules are different. All these rules introduce more volatility in future tax rates than the constant-tax-rate rule. I distinguish fiscal rules along three dimensions. The first is whether taxes or government spending adjusts to stabilise debt. The second is whether the long-run government debt-to-GDP ratio is fixed exogenously, or is a function of the history of shocks. The third dimension is whether the fiscal authority looks forward or only backward. Most rules only look backward, though the MULTIMOD Mark III rule, equation (3) above, looks forward to a limited extent.

Fiscal rules which adjust taxes typically have the functional form

$$
\Delta \tau_{t}=A L\left(\left(\frac{B}{Y}\right)_{t-1}-\left(\frac{B}{Y}\right)^{*}\right)
$$

\footnotetext{
${ }^{8}$ This is the approach of Levin, Rogers and Tryon (1997) using the Fed's FRB/Global model.

${ }^{9}$ For example, see Finan and Tetlow (2000) for a derivation of the optimal monetary rule in the FRB/US model.

${ }^{10}$ See Kotlikoff's (1998) summary of work using the Auerbach-Kotlikoff model.
} 
where $\Delta$ is the one-period change in any variable, $Y$ is nominal GDP and $A L($.) represents some lag structure with various coefficients on the lags. Equilibrium, with constant tax rates and debt ratios, may or may not require the debt ratio to be at its target $(B / Y)^{*}$, depending on the precise functional form. The right-hand side typically includes lags but not leads, implying the fiscal agency only looks backward. The debt target $(B / Y)^{*}$ may differ by period, but existing literature proposes no principles by which it does so. Examples of roughly this functional form include

$$
\begin{aligned}
& \text { IMF MULTIMOD II }{ }^{11} \quad \Delta \tau_{t}=\alpha\left(\frac{B_{t-1}-B^{*}{ }_{t-1}}{Y_{t-1}}\right)+\beta \Delta\left(\frac{B_{t-1}-B^{*}{ }_{t-1}}{Y_{t-1}}\right) \\
& \mathrm{FRB} / \mathrm{US}^{12} \quad \Delta \tau_{t}^{t r e n d}=\alpha\left(\left(\frac{B}{Y}\right)_{t-1}-\left(\frac{B}{Y}\right)_{t-1}^{*}\right)+\beta \Delta\left(\left(\frac{B}{Y}\right)_{t-1}-\left(\frac{B}{Y}\right)_{t-1}^{*}\right) \\
& \mathrm{QPM}^{13} \quad \tau_{t}=\eta \cdot \tau_{t-1}+(1-\eta)\left(\tau^{*}+\beta\left(\left(\frac{B}{Y}\right)_{t-1}-\left(\frac{B}{Y}\right)^{*}\right)\right),
\end{aligned}
$$

where $\tau *$ is the steady-state tax rate implied by the steady-state debt ratio $(B / Y)^{*}$ and an exogenously given level of government spending;

$$
\begin{array}{cc}
\mathrm{NIGEM}^{14} & \Delta \tau_{t}=\gamma\left(\left(\frac{\Delta B}{Y}\right)_{t-1}-\left(\frac{\Delta B}{Y}\right)_{t-1}^{*}\right) \\
\mathrm{EDGE}^{15} & \Delta \tau_{t}^{\text {direct }}=\alpha\left(\left(\frac{B}{Y}\right)_{t-1}-\left(\frac{B}{Y}\right)^{*}\right)+\beta\left(\left(\frac{\Delta B}{Y}\right)_{t-1}-\left(\frac{B}{Y}\right)^{*}\left(\pi_{t-1}+g\right)\right)
\end{array}
$$

where $\pi$ is the inflation rate and $g$ the steady-state growth rate of real GDP. The Reserve Bank of New Zealand's FPS model (see Black et. al. 1997) includes a similar backward-looking fiscal rule, though since it involves several equations, I omit it here. Note that a target for the debt ratio will imply a target for the deficit ratio and vice versa. Since steady-state nominal GDP grows at an exogenous rate $n$, in steady state

\footnotetext{
${ }^{11}$ MULTIMOD Mark II, Masson, Symansky and Meredith (1990). Laxton et. al. (1998) state that MULTIMOD Mark III has the same rule as Mark II. But the version of Mark III on the web has the qualitatively different rule given in equation (3) in the text.

${ }^{12}$ Brayton and Tinsley (1996) describe the FRB/US model but do not give equations. These are available upon request from David Reifschneider of the Federal Reserve Board at

David.L.Reifschneider@bog.frb.gov.

${ }^{13}$ Bank of Canada Quarterly Projection Model. Coletti et. al. (1996) quote equation (15) as being a 'stylized version' of QPM's fiscal reaction rule. Mr. Coletti kindly sent me the actual model equation, which has some additional terms. Its sense is accurately conveyed by equation (15), however.

${ }^{14}$ National Institute (UK) General Equilibrium Model. I quote this rule from Mitchell et. al. (2000)

${ }^{15}$ Euro-Area Dynamic General Equilibrium Model, Mika Kortelainen, Bank of Finland, 2000.
} 


$$
\left(\frac{\Delta B}{Y}\right)^{*}=n \cdot\left(\frac{B}{Y}\right)^{*}
$$

Fiscal feedback rules could relate tax rates or the change in tax rates to a nonlinear function of the debt ratio. For example, the U.S. Federal Reserve's FRB/Global model ${ }^{16}$ includes:

$$
\tau_{t}=k+m\left(\left(\frac{B}{Y}\right)_{t-1}-\left(\frac{B}{Y}\right)^{*}\right)\left|\left(\frac{B}{Y}\right)_{t-1}-\left(\frac{B}{Y}\right)^{*}\right|
$$

Yet another rule, in the Auerbach-Kotlikoff model, keeps the ratio of government debt to effective workers constant through time using changes in tax rates. ${ }^{17}$ Auerbach and Kotlikoff also keep the ratio of government spending to effective workers constant, which will tend to limit tax-rate volatility. In general, an arbitrary fiscal rule may induce attractive paths of the economy after some shocks, but unpleasant paths after others.

By contrast, some fiscal rules achieve a debt target by changing government spending. The European Commission's QUEST model, for example, prevents debt from exploding by changing government transfers to households:

QUEST II $^{18} \quad \Delta$ RRH $_{t}=\alpha\left[\left(\frac{B}{Y}\right)_{t}-\left(\frac{B}{Y}\right)^{*}\right]+\beta\left[\left(\frac{B}{Y}\right)_{t}-\left(\frac{B}{Y}\right)_{t-1}\right]$,

This is problematic since attractive paths of GDP can be achieved by cutting current taxes, as transfers then automatically fall. While economists may wish deliberately to simulate a cut in transfers, assuming this happens automatically to achieve debt stability may confuse analysis of other tax reforms.

Fiscal reaction rules working through government spending are subject to the same criticism. The Bundesbank's MEMMOD model ${ }^{19}$ stabilises German debt-toGDP in this manner:

$\Delta \log G C_{t}=\alpha+\beta \Delta \log W_{t-1}-A L\left(\frac{\Delta B}{Y}\right)_{t}+\gamma \Delta \log G C_{t-1}+A L\left(\log G A P_{t}\right)$

where $G C$ is government consumption, $W$ are negotiated nominal wages, $A L($.) again represents some lag structure, and $G A P$ is the gap between actual and potential capacity utilisation. I have simplified the MEMMOD equation by omitting the 'time since unification' terms. With this rule tax cuts could produce attractive simulation results by forcing government consumption, including defense spending, to fall to zero. Again this would confuse the effect of tax changes with those of other reforms.

\footnotetext{
${ }^{16}$ FRB/Global, Levin, Rogers and Tryon, 1997.

${ }^{17}$ Kotlikoff (1998), in his appendix states this in words, though without an equation.

${ }^{18}$ QUEST II, Roeger and in 't Veld, European Commission, 1997.

${ }^{19}$ Deutsche Bundesbank, MEMMOD: Multi-Country Economic Model, June 2000.
} 
While the Bundesbank's rule is rare in using government consumption to stabilise debt, the modelling of government spending is highly relevant to fiscal rules' performance. For example, in an equation for government consumption such as

$G C_{t}=k Y_{t}$,

the parameter $k$ will affect the degree of tax response to a recession necessary to stabilise debt in the long run. In this paper I treat government consumption as being exogenously determined. Theories of its optimal or empirical determination may be preferable.

While some rules force the debt-GDP ratio to hit a specified target, others ensure only that this ratio stabilises at a level determined by the history of shocks. The constant-tax rule exhibits 'historical shock dependence'. To see this, return to equation (2), make the tax rate constant and take the limit as the 'end date' tends to infinity. We have

$$
\tau \int_{0}^{\infty} c(s, \tau) e^{-r s} \cdot d s=B_{0}+\int_{0}^{\infty} G(s) e^{-r s} . d s
$$

where I have made explicit the dependence of the consumption level on the constant tax rate. Suppose an unexpected war temporarily raises government consumption $G$. The tax rate rises in all periods. After the war, when $G$ has fallen again, the higher tax rate is consistent with debt stability only if there is now more debt to service. Since the tax rate rises only slightly on news of the war, the government pays for the war by issuing new debt, which is serviced forever. Total output after the war will be either the same or lower than had no war occurred. In either case, the debt-GDP ratio will be higher forever due to this episode.

Most fiscal rules in current use, however, constrain the debt ratio to return to a pre-specified target. As was argued in section three, this will be sub-optimal in almost any model. Following Masson et. al. (1990), FRB/Global like other models targets the starting-period debt-ratio. This implies the model baseline features almost constant tax rates, but also that debt targets must differ widely by country. Table 1 , taken from Levin, Rogers and Tryon (1997), shows FRB/Global's debt-ratio targets for the G7 economies. They are the debt-to-GDP ratios in 1995. Pre-specifying debt targets typically means tax rates oscillate substantially after a shock, as is shown below. The steady-state debt ratio affects steady-state debt output, due to distortionary taxation and, in overlapping-generations models, because government debt 'crowds out' private capital. Therefore a positive implication of most current fiscal rules is that "the steady state will not change owing to....any [temporary] shock". ${ }^{20}$ This interesting feature of macro models is thus driven by an arbitrary assumption rather than anything fundamental about economics.

Another important difference between rules is whether the fiscal authority looks forward or only backward. The only forward-looking rule I have found in use is the MULTIMOD Mark III rule, equation (3). Here the tax rate depends on debt last

${ }^{20}$ Coletti et. al., (1996) 
period but also on the tax rate two periods in the future and two periods in the past. By induction the tax rate in each year depends on the debt ratio in every period. This creates some smoothness in the tax rate, which starts to rise, for example, before an increase in government consumption. Rule (3) does not impose a constant tax rate. As is shown below, after a shock it returns the debt ratio fairly rapidly to its exogenous target, thereby creating substantial unnecessary fluctuation in the tax rate. Thus in practice rule (3) behaves rather similarly to a backward-looking rule.

\section{The Simulation Performance of Current Fiscal Rules}

The choice of fiscal reaction rule affects the short and long-run simulation performance of current macroeconomic models. Taxes distort markets, but also have Keynesian effects because private consumption depends heavily on current income. For example, figures 2(a) to (d), taken from Mitchell et. al. (2000), compare simulations using the MULTIMOD Mark II and NIGEM fiscal rules (9) and (12). Both are backward-looking tax adjustment rules. To isolate the influence of the fiscal rules, each is simulated in the same macroeconomic model, in this case NIGEM. The $x$ axis in each figure measures time in years and the $y$ axis percentage deviations from the baseline simulation. At time zero, government consumption is permanently reduced by 1 percent of GDP compared to the baseline, and the debt-to-GDP target is reduced by 10 percentage points relative to that in the baseline. Three points are apparent from a comparison of the reaction rules in figures 2(a) to (d). First, figures 2(a) to 2(c) show that the time-path of tax revenues and thus debt differs substantially across rules. The debt ratios are very different after the thirty years of simulations shown in figure 2(a), but eventually they are equal. Second, figure 2(c) shows that tax revenues are smoother under the NIGEM rule than under the MULTIMOD II rule. Third, the evolution of GDP varies substantially according to which reaction rule is chosen, and since taxes are smoother under the NIGEM rule, in figure 2(d) GDP is smoother for this rule. These figures show that the choice of fiscal rules substantially affects simulation outcomes. This makes their arbitrary specification in current practice rather worrying.

\section{Implementation and Performance of the Constant-Tax Rule}

This section has three parts. The first describes the MULTIMOD model in which I impose the constant tax rate. The second explains in detail how I do so. Of necessity my implementation method makes the tax rate almost but not entirely constant. Sensitivity analysis shows the remaining non-constancy does not affect the simulation results significantly. The third part gives the simulation results of the constant tax rate and compares them to those given by MULTIMOD's existing fiscal rule.

\section{The MULTIMOD Mark III Model}

MULTIMOD Mark III is arguably not the ideal model in which to test the constant-tax rule, since it allows taxes to have income but few substitution effects. Labour supply, for example, is determined exogenously. Private consumption is determined in a forward-looking manner, but also depends heavily on disposable 
income, so the time-path of taxes affects consumption and output for Keynesian reasons. Interest rates depend on world government debt. There is a tax on capital income, and a 'tax on households' which can be interpreted as being levied on labour income. I concentrate on the path of the total tax rate, or tax revenues as a proportion of national income, since this is adjusted by MULTIMOD's existing reaction rule. Movements in this tax change taxes on both labour and capital. Allowing tax adjustment to occur only through labour taxes would be a fairly straightforward modification. I present simulation results for single countries, although each simulation solves for variables in the entire world economy.

\section{Implementing the Constant Tax Rate}

MULTIMOD Mark III has, like most numerical macro models, a long-run solution algorithm (ssmark3) and a dynamic-path solution algorithm (mark3). The modeller starts each simulation by sending a list of exogenous parameter values to the long-run programme ssmark3. The steady-state debt ratio is, in MULTIMOD, exogenous. The long-run algorithm solves for the endogenous variables for some period far in the future, in my simulations from 2150 to 2160 . These values are then inputs for the dynamic algorithm mark3. The modeller then tells the dynamic algorithm when to start the simulation, here always in 2010, and a further set of parameter values obtaining from the start until the steady state. This algorithm then solves for the endogenous variables during this period. The dynamic algorithm assumes rational expectations under certainty by setting the tax rate consumers in year $n$ expect to obtain in period $n+t$ to precisely the tax rate obtaining in year $n+t$.

Figure 3 illustrates an exercise involving only the steady-state model ssmark3. I send a long-run debt ratio $b$ and a government consumption share-of-GDP to this algorithm, which returns the necessary steady-state tax rate $\tau$. With repetition, I would have many points on a line of possible combinations $(\tau, b)$, such as those in figure 3. Note that a different rate of government spending in steady-state will define a different line of $(\tau, b)$ combinations. In MULTIMOD, these lines are straight, but my use a one-dimensional search algorithm requires only the weaker condition that the possible $(\tau, b)$ combinations trace a one-dimensional space.

The one-dimensionality of possible $(\tau, b)$ combinations in steady state implies one condition is needed to fix an 'ideal' $\left(\tau^{*}, b^{*}\right)$ combination. I use the condition $\dot{\tau}=0$. Though analytical methods may not tell me which point this condition determines, a search algorithm can find it. Imposing the constraint $b_{S S}=b_{\text {INITIAL }}$ would in general determine a different $b_{S S}$, making $\dot{\tau}=0$ impossible. My algorithm imposes an arbitrary $(\tau, b)$ combination from the steady-state model ssmark3 on the dynamic model mark 3 to see how far is from being consistent with $\dot{\tau}=0$. Imposing $\dot{\tau}=0$ for all time would run into the inconsistency necessarily present, and the algorithm mark 3 would fail to converge and give no results. For this reason in mark3, given the existing reaction rule

$$
\tau_{s}=\tau_{X}(1-\alpha)+\alpha\left(\sum_{i=s-2}^{i=s+2} \tau_{i}+\delta\left(\frac{B_{s-1}}{Y_{s-1}}-\left(\frac{B}{Y}\right)^{*}\right)\right)
$$


I set

Exogenous shock to government consumption or money supply

Debt Target $=b^{*}$ in all periods

Exogenous tax rate $\tau_{X}=\tau^{*}$ from 2010 to 2040

Fiscal reaction parameter $\alpha=0$ from 2010 to $2040, \alpha=1$ thereafter

The standard fiscal rule is thus 'switched off' until 2040, so the tax rate is fixed at $\tau_{X}=\tau^{*}$ until 2040. From 2040 the standard rule will force the debt ratio back towards its target, so the dynamic algorithm mark3 will converge to a solution. In general the tax rate will jump either up or down in 2040 when the standard rule is switched on. If the jump in the first simulation is upwards, debt was above its target in 2040 so I run the next simulation with a new $(\tau, b)$ combination where both are higher. The reverse is true if the jump was downwards. In this manner I converge on a $\left(\tau^{*}, b^{*}\right)$ combination where the jump in the tax rate in 2040, and thus the deviation from $\dot{\tau}=0$, is very small. ${ }^{21}$

This algorithm finds the constant tax rate $\tau^{*}$ consistent with long-run stability of the debt-GDP ratio. It is not, in fact, possible to impose $\dot{\tau}=0$ precisely. As is discussed below, the debt ratio would approach its steady-state level smoothly were the simulation run for an infinite future. Since my simulations impose the steady-state debt level after a finite time, there must be some non-smoothness of the debt path and consequently a 'wobble' in the tax rate. The arbitrary element of the algorithm is the date, which I denote $2010+F$, at which the standard fiscal rule is 'switched on', causing this tax wobble. My computer ran out of memory whenever I set $F>30$. For $F=20$, the minimal-jump combination of $\left(\tau^{*}, b^{*}\right)$ was very close to that for $F=30$. Therefore in this range the choice of $F$ made little difference to the simulation results. Table 3 compares the quantitative results of setting $F=20$ and $F=30$. The differences are minor. ${ }^{22}$ My use of an arbitrary standard fiscal rule ensures the model solves, but does not determine the nature of the simulation results.

\section{Simulated Responses to a Government Spending Shock}

The MULTIMOD baseline sets government consumption as a fixed proportion of GDP. I simulate the shock of, from 2010 onwards, reducing German government consumption by 1 percent of GDP. My simulations start in 2010 so the shock is a surprise in that year but not afterwards. Figure 4 shows the constant tax rate (denoted 'FORWARD') implemented in response to this shock, and also that given by MULTIMOD III's existing rule (denoted 'BACK', though it is not entirely backwardlooking). ${ }^{23}$ Both tax rates equal the baseline before the simulation starts in 2010 . The constant-rate tax falls dramatically in 2010, and is then constant but for a small wobble in 2040. By contrast, the standard-rule tax rate does not fall as far in 2010 or 2011. By 2012 it is very similar to the constant-rate tax, but since government debt is falling in 2012 (see figure 7 below), the tax rate must fall further to stabilise debt, as it

\footnotetext{
${ }^{21}$ I found the initial tax rate which, to six decimal places, induced the smallest tax jump in 2040.

22 'Aggregate utility' is higher when $\mathrm{F}=20$ than when $\mathrm{F}=30$, although taxes are smoother when $\mathrm{F}=30$. This reflects the slightly lower initial tax when $\mathrm{F}=20$. This result shows that, although tax-smoothing is optimal in a specific analytical model, it may not be optimal in a given macroeconomic model.

${ }^{23}$ Since all numerical models are discrete, the lines joining each simulation outcome in these figures have no meaning. The figures are very difficult to understand without the connecting lines, however.
} 
does in 2013 and 2014. The standard fiscal rule imposes a debt-ratio target very close to that in the baseline for 2010. Therefore the tax rate under the standard rule must rise from 2016 onwards to make the debt ratio increase again. The tax rate then overshoots the constant-rate tax again, before declining gradually from 2022 to 2149 . Although figure 4 shows only one standard fiscal rule in operation, generally tax rates cannot be always above or always below the constant-rate tax without debt exploding. Therefore any other fiscal rule must make tax rates 'overshoot' those given by the constant tax rate rule.

Figure 5 compares the evolution of German GDP under the constant-tax and standard fiscal rules. The units of the $y$ axis are percentage differences from the baseline simulation, which itself is essentially smooth after 2010. The surprise of the decline in government consumption starting in 2010 reduces demand and thus output that year. Reductions in taxes increase disposable income and thus, in this model, private consumption. The size of the fall in output depends heavily on the reduction in taxes in 2010. We see in figure 4 that, because the constant-rate tax falls sharply in 2010, the fall in GDP that year is only about 0.2 percent. Under the standard rule, the tax rate falls less in 2010 so output falls three times as much, by 0.6 percent. The taxrate overshooting apparent under the standard rule in figure 4 then makes GDP rise above baseline from 2013 to 2018. Overall GDP follows a smoother path after the initial shock under the constant-tax rule. There is a very small fluctuation of GDP after 2040 under this rule because of the 'wobble' in the tax rate at this point.

Private utility may depend on consumption and leisure. Figure 6 shows the time-paths of private consumption under the constant-rate and standard fiscal rules. Consumption in MULTIMOD is particularly sensitive to current disposable income, though it also depends on income from the entire future. Therefore the large cut in taxes in 2010 under the constant-tax rule induces a large increase in consumption that year. Thereafter consumption grows fairly smoothly, though again with a small fluctuation after 2040. Under the standard fiscal rule, consumption reflects the sluggish adjustment of the tax rate by rising more slowly in 2010 to 2012, but then shooting over and then under the consumption path under the constant-tax rule. I construct 'aggregate utility' from these two consumption paths from 2010 to $3010^{24}$ using the iso-elastic utility function

$U=\sum_{S=1}^{S=N} \frac{c_{s}{ }^{1-\theta}}{1-\theta}(1+\rho)^{-s}$

where $\theta$ reflects a consumer's willingness to substitute consumption over time and $\rho$ is the private rate at which future flows of utility are discounted back to the present. Ideally I would compare utility from consumption until infinity; lacking an expression for (19) as $N \rightarrow \infty$ I cannot do this, but the net present value of differences after 3010 is probably small. Table 2 shows the calculated percentagepoint increase in 'aggregate utility' from consumption under the constant-tax rule compared to the standard MULTIMOD rule, for values of $\theta$ from 1 to 4 and values of $\rho$ from 0.03 to 0.09 . The utility increases are all positive, so for a wide range of parameter values the constant-tax rule produces preferable consumption paths. The

\footnotetext{
24 The MULTIMOD simulations run to 2149, from which date I extend the consumption series forward at their trend growth rates of 2.2007 percent per year.
} 
increases are small; if, for example, $\theta=1$ (log utility) and $\rho=0.03$, 'aggregate utility' is raised by only 0.001 of one percentage point. This is because the rules induce very similar long-run consumption paths. Arguably an increase in total utility of 0.1 to 0.3 percent is important, however. The utility differences increase with higher $\theta$ and $\rho$ as both make the differences in consumption in 2010 to 2012 more important.

Figure 7 shows the paths of the debt-to-GNP ratios ${ }^{25}$ for the constant-tax and standard fiscal reaction rules. Under the constant-tax rule, turning the standard rule off and later on again creates a 'shoulder' to the debt ratio at the 'switch-on' date of 2040. Since the debt ratio rises to the left of the 'shoulder' and is constant to its right, the tax rate must jump slightly in 2040. A later 'switch-on' date, previously denoted $2010+F$, would make debt approach its asymptote more smoothly, so the debt 'shoulder' would be smoother and the tax wobble smaller. The logic of this effect is as follows. A higher initial tax rate would make the debt ratio climb less initially, so the 'shoulder' in the debt ratio when it becomes constant will be smoother. A higher tax rate would imply a higher steady-state debt ratio. Slower initial debt growth and a higher steady-state debt ratio are mutually consistent only if the switch-on date is later. As was shown in table 3, for this shock the difference in results between setting $F=20$ and $F=30$ is negligible. Another way of showing this near-invariance is to compare the time-path of GDP under the constant-tax rule in figure 8 , produced with $F=20$, to that in figure 5, produced with $F=30$. The evolution of GDP under the constant-tax rule is very similar between the figures.

\section{Simulated Responses to a Monetary Shock}

I now test the sensitivity of model responses to a monetary shock to the choice of fiscal rule. I simulate a permanent and unexpected 10 percent increase in the Canadian money supply target under MULTIMOD's standard fiscal rule and the constant-tax rule. The Canadian monetary-policy equation makes the short-run interest rate endogenous to exchange rates, the money supply and its target. A permanently higher money supply target leads to a brief period of lower short-run interest rates. The constant-tax rule was derived as being optimal in a non-monetary economy, so I do not claim that it represents the optimal response to this monetary disturbance. The simulations show that GDP and inflation are more stable under the constant-tax rule, and that 'long-run neutrality' to monetary shocks depends on whether the fiscal rule returns the debt ratio to its starting value. I conclude that the choice of fiscal rule is of some relevance to analysis of monetary policy.

Figure 9 shows the paths of the inflation rate across the money-target increase, a surprise when it occurs in 2010. The simulations compare outcomes under MULTIMOD's existing fiscal rule (denoted 'BACK') and the constant-tax rule (denoted 'FORWARD'). Inflation rises above its baseline initially in both cases, consistent with a monetary expansion. Inflation rises higher under the standard fiscal rule, however, since fiscal policy adds to the monetary expansion. Figure 10 displays the paths of the short-term interest rate in each scenario. The short interest rate is more stable under the constant-tax rule, again because it need not counteract fluctuating tax rates. Figure 11 shows the tax rates in each simulation. Under the standard rule, the tax rate falls substantially at first because the monetary expansion

\footnotetext{
${ }^{25}$ The MULTIMOD III rule targets a ratio of debt to GNP rather than GDP.
} 
has raised output and reduced debt. The tax rate later overshoots its initial value. Under the constant-tax rule, the tax rate falls once only, by a small amount reflecting temporarily higher output. Figure 12 compares the paths of the debt-GNP ratio; the constant-tax rule translates higher initial output into a permanently lower debt ratio. The standard rule returns the debt ratio to its baseline level. This difference in longrun debt ratios drives the different long-run levels of GDP shown in figure 13. Since the constant-tax rule makes the long-run debt ratio endogenous to shocks, real variables' long-run values are slightly affected by nominal shocks. The constant-tax rule also produces a smoother path of GDP, with the initial boom around 0.8 percent of GDP smaller and the subsequent recession 0.9 percent smaller. Overall these comparisons show some sensitivity of model outcomes on the fiscal rule for a monetary shock, and a qualitative difference in the long-run response.

\section{'Sticky Taxes' under Backward and Forward-Looking Rules}

Institutional constraints may prevent fiscal authorities from responding to shocks for a finite period. Later they must respond by changing spending or taxes, to prevent debt explosion. Thus the tax rate may exhibit short-run 'stickiness'. Simulations involving 'sticky taxes' are at present run in macro models (see Levin, Rogers and Tryon 1997) by imposing an unchanged tax rate for the first, say, ten years and 'switching on' a fiscal rule only then. If the fiscal rule targets a predetermined debt ratio, turning it on at year ten can result in wild fluctuation of the tax rate, since the debt ratio may then be far from its target. If debt has fallen, standard rules may use fluctuating taxes to raise the debt ratio to its historical level, whereas preserving the lower debt ratio would be a more natural goal. The constant-tax approach is to find the new sustainable constant tax rate at the turn-on point and immediately move the tax rate there.

The standard and constant-tax approaches to a 'sticky tax' are compared in figures 14, 15, 16 and 17. In each case, German government spending in each year from 2010 decreases by 1 percent of GDP, but the fiscal authority does not change taxes until 2020. Figure 14 shows the paths of the tax rate under the standard (again denoted 'BACK') and constant-tax ('FORWARD') approaches. The backwardlooking approach forces the tax rate to fall heavily in 2020 so as to raise the debt ratio to its target. Under the constant-tax approach, the tax rate falls much less but is stable at its new level. Figure 15 compares the implied paths of the debt ratio. Lower government spending with no tax-rate response reduces the debt ratio under both approaches until 2020. From 2020, the constant-tax approach accepts the lower debt ratio but the standard rule returns the debt ratio to its predetermined target. Figure 16 compares the paths of GDP, and figure 17 those of private consumption, showing both to be far more volatile under the standard fiscal rule. Both long-run consumption and GDP are lower under the standard fiscal rule, since the long-run debt ratio is higher. Since we wish to avoid consumption volatility, figures 14 through 17 suggest the standard approach to fiscal reaction rules performs particularly poorly if the fiscal authority is constrained not to respond to a shock for some period. 


\section{Conclusion}

This paper identifies a 'fiscal rule problem' and suggests a solution. Fiscal reaction rules in current macro models are not derived from any optimising framework. Since they generally involve the fiscal authority looking only backwards, they cannot be construed as optimal in any possible model. Beyond the plausible assumption that fiscal policy responds to shocks only with some lag, they are not justified by any empirical arguments either. From a positive perspective, model responses to any shock depend on the fiscal rule, so use of arbitrary rules may detract from models' usefulness in guiding monetary policy. From a normative perspective, we may worry that arbitrary fiscal assumptions impede our ability to evaluate different policies.

Political competition may force fiscal agencies to behave optimally. The constant future tax rate is optimal within a market-clearing, perfect-foresight model with one generation of consumers. It is sub-optimal in other models. Generally, however, optimal fiscal policy will be forward-looking, and make all tax rates, and thus the debt ratio at all dates, endogenous to the history of shocks. Debt-stabilising fiscal rules may be compared by the utility-value of the time-paths of consumption and leisure they induce. In MULTIMOD, the constant-tax rule allows more stable and overall preferable consumption to MULTIMOD's existing fiscal rule. The gain in 'aggregate utility' from using the constant-tax rule depended on the preference parameters, but for plausible values is around 0.1 percent.

Model simulations could be presented using the preferred fiscal rule, or some small set of preferred alternatives. Since applied macroeconomists typically find models with overlapping generations plausible, characterisations of optimal fiscal policy within such models might provide one such preferred option. Careful empirical descriptions of fiscal policy might provide others. Since model outcomes are sensitive to the fiscal rule chosen, use of arbitrary rules on the grounds that debt must be controlled somehow does not seem defensible. 


\section{Bibliography}

Anderson, Gary, A Reliable and Computationally Efficient Algorithm for Imposing the Saddle-Point Property in Dynamic Models, Federal Reserve Board Occasional Staff Studies Series 4, September 2000, www.bog.frb.fed.us/pubs/oss/oss4/papers.html.

Barro, Robert, On the Determination of the Public Debt, Journal of Political Economy Vol. 87 No. 5 Part 1, October 1979.

Barro, Robert, Optimal Debt Management, NBER Working Paper 5327, October 1995.

Black, Richard; Cassino, Vincenzo; Drew, Aaron; Hansen, Eric; Hunt, Benjamin; Rose, David, and Scott, Alasdair, The Forecasting and Policy System: The Core Model, Reserve Bank of New Zealand, Research Paper no.43, August 1997, www.rbnz.govt.nz/research/econresearch/rp43.pdf

Brayton, Flint, and Tinsley, Peter, eds., A Guide to FRB/US, Federal Reserve Board Finance and Economics Discussion Series 1996-42, www.federalreserve.gov/pubs/feds/1996/199642/199642pap.pdf

Chari, V.V., and Kehoe, Patrick, Optimal Fiscal and Monetary Policy, NBER Working Paper 6891, January 1999.

Coletti, Donald; Hunt, Benjamin; Rose, David and Tetlow, Robert, The Bank of Canada's New Quarterly Projection Model, Part 3: The Dynamic Model: QPM. Bank of Canada Technical Reports No. 75, May 1996, available at www.bankofcanada.ca/publications/techreports/tr75.pdf

Deutsche Bundesbank, MEMMOD: Multi-Country Economic Model, June 2000.

Finan, Frederico S., and Tetlow, Robert, Optimal Control of Large, Forward Looking Models; Efficient Solutions and Two Examples, Federal Reserve Board Finance and Economics Discussion Series 1999-51, www.federalreserve.gov/pubs/feds/1999/199951/199951pap.pdf.

Kortelainen, Mika, Actual and Perceived Monetary Policy Rules in a Dynamic General Equilibrium Model of the Euro Area, Bank of Finland, unpublished, 2000.

Kotlikoff, Laurence, The A-K Model - Its Past, Present and Future, NBER Working Paper 6684, August 1998.

Kozicki, Sharon, and Tinsley, P.A., Term structure views of monetary policy under alternative models of agent expectations, Journal of Economic Dynamics and Control, Vol. 25, 2001, p.149-184.

Laxton, Douglas, Isard, Peter, Faruqee, Hamid, Prasad, Eswar, and Turtelboom, Bart, MULTIMOD Mark III: The Core Dynamic and Steady-State Models, IMF Occasional Paper 164, 1998, www.imf.org/external/pubs/ft/op/op164/index.htm. 
Levin, Andrew T, Rogers, John H., and Tryon, Ralph W., A Guide to FRB/Global, Board of Governors of the Federal Reserve System, International Finance Discussion paper 588, August 1997, www.bog.frb.fed.us/pubs/ifdp/1997/588/default.htm.

Lucas, Robert E., Econometric Policy Evaluation: A Critique, in The Phillips Curve and Labour Markets, ed. Brunner, Karl and Meltzer, Allan H., Carnegie-Rochester Conference Series on Public Policy, Vol. 1, 1976.

Masson, Paul R., Symansky, Steven, and Meredith, Guy, MULTIMOD MARK II: A Revised and Extended Model, IMF Occasional Paper 71, 1990.

Mitchell, Peter, Sault, Joanne, and Wallis, Kenneth, Fiscal policy rules in macroeconomic models: principles and practice, Economic Modelling No.17, 2000.

Roeger, Werner, and in 't Veld, Jan, QUEST II, A Multi Country Business and Growth Model, European Commission 1997. 


\begin{tabular}{|l|c|}
\hline \multicolumn{2}{|c|}{ Table 1: Baseline Debt-GDP Targets for the Fed's FRB/Global Model } \\
\hline Country & (B/Y)* \\
\hline United States & 49 \\
\hline Germany & 77 \\
\hline Japan & 59 \\
\hline Canada & 107 \\
\hline France & 44 \\
\hline Italy & 119 \\
\hline United Kingdom & 56 \\
\hline \multicolumn{2}{|l}{ Source: Table C2, Levin, Rogers and Tryon, A Guide to FRB/Global, 1997. The } \\
targets are the average debt-GDP ratios in 1995.
\end{tabular}

Table 2: Percentage-Point Increase in Aggregate Utility of Consumption Path, Constant-Tax Rule over Standard Rule

\begin{tabular}{|c|c|c|c|c|}
\hline & \multicolumn{4}{|c|}{$\theta$} \\
\hline & 1 & 2 & 3 & 4 \\
\hline$\rho$ & & & & 0.131 \\
\hline 0.03 & 0.001 & 0.042 & 0.166 & 0.309 \\
\hline 0.05 & 0.004 & 0.062 & 0.199 & 0.357 \\
\hline 0.07 & 0.007 & 0.08 & 0.23 & 0.403 \\
\hline 0.09 & 0.009 & 0.096 & 0.2 & \\
\hline
\end{tabular}

Note: aggregate utility is constructed from aggregate private consumption from 2010 to 3010, using the iso-elastic utility function, equation (13) in the text. Private consumption is simulated until 2149 and assumed to grow at the trend rate of 2.2007 percent per year thereafter.

\begin{tabular}{|c|c|c|c|c|c|c|}
\hline \multicolumn{7}{|c|}{$\begin{array}{l}\text { Table 3: Sensitivity Analysis of Implementation of the Constant Tax. } \\
\text { Arbitrary Choice is Date 2010+F when Standard Fiscal Rule is Turned On. }\end{array}$} \\
\hline & $\begin{array}{l}\text { Tax Rate } \\
\text { in } 2010\end{array}$ & $\begin{array}{l}\text { Long-Run } \\
\text { Debt Ratio }\end{array}$ & \multicolumn{2}{|c|}{$\mathrm{GDP}^{1}$ in } & 2012 & $\begin{array}{l}\text { Total Utility, } \\
\rho=0.05, \theta=2 \text {. }\end{array}$ \\
\hline \multicolumn{7}{|l|}{ Fiscal Rule } \\
\hline \multicolumn{7}{|l|}{ Constant Tax } \\
\hline $\mathrm{F}=30$ & 0.19935 & 0.33757 & -0.21 & -0.13 & -0.05 & 1.00062 \\
\hline $\mathrm{F}=20$ & 0.199299 & 0.33645 & -0.21 & -0.13 & -0.05 & 1.00064 \\
\hline $\begin{array}{l}\text { Standard Rule } \\
\text { Only }\end{array}$ & 0.209385 & 0.327321 & -0.6 & -0.27 & 0.02 & 1 \\
\hline
\end{tabular}


Figure 1: Government Debt-GNP Ratio, Government Spending Up by $0.5 \%$ of GDP in 2010 Only, Fiscal Closure Rule Turned Off Until 2040.

MULTIMOD model of Germany.

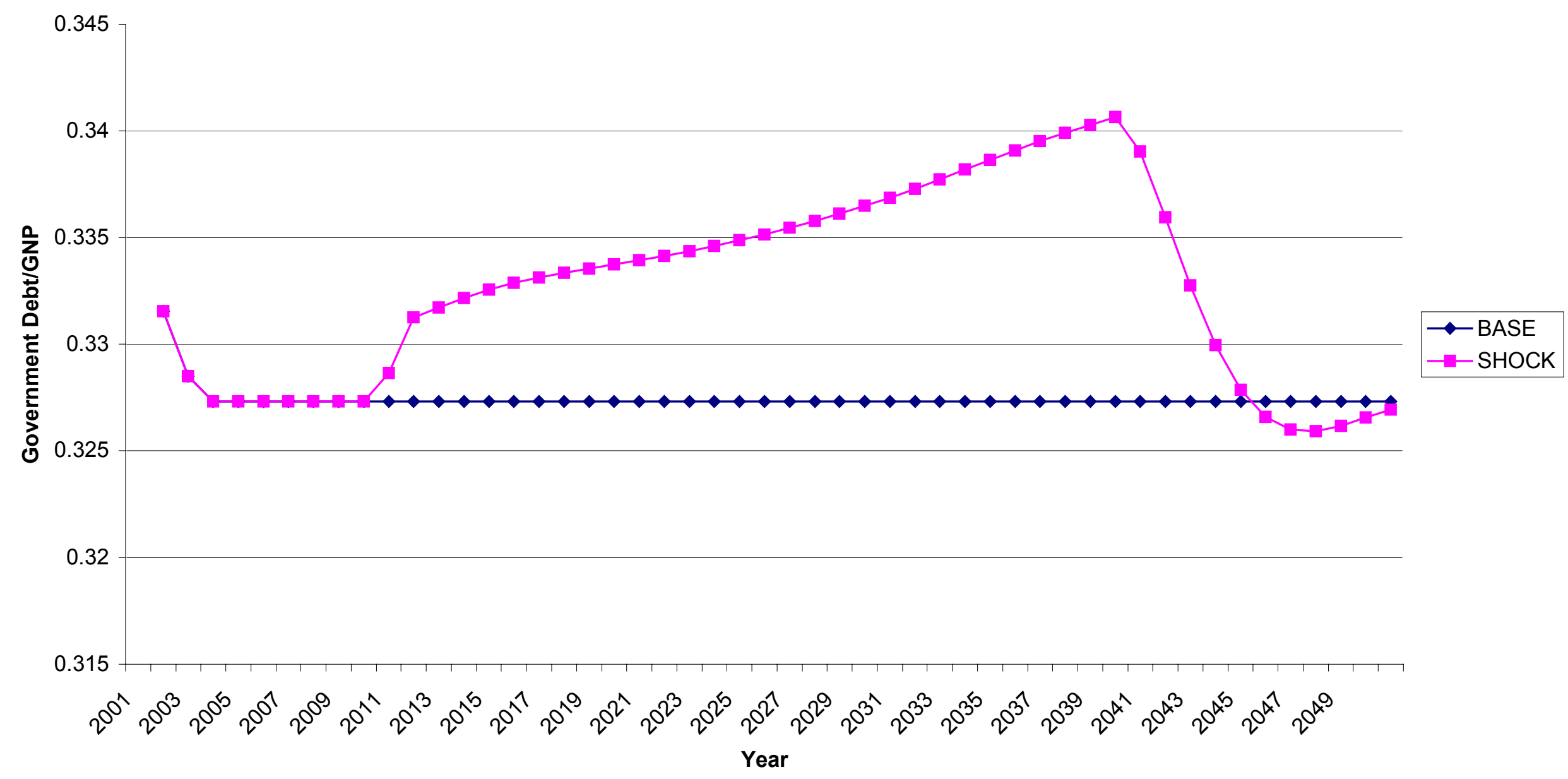



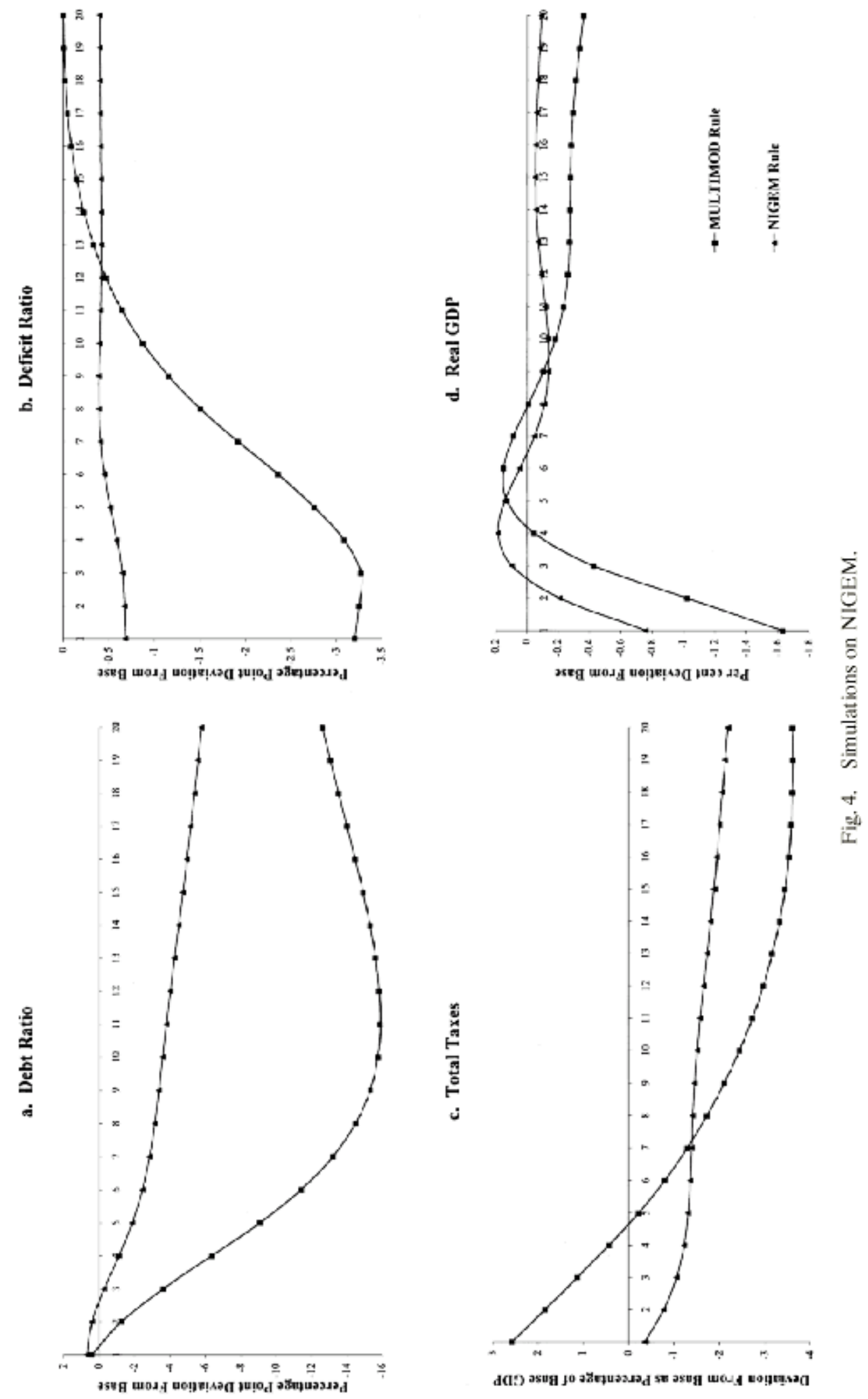

Figure 2: Sensitivity of Macro Models to Fiscal Reaction Rules

Taken from Mitchell et. al., 2000. The NIGEM, and MULTIMOD rules were each applied to the NIGEM model. Here a permanent $1 \%$ cut in government spending and a long-run reduction in the debt-GDP ratio by $10 \%$ were simulated. 
Figure 3: Tax-Rate and Debt-Ratio Combinations (t,b) in Steady State, MULTIMOD Germany

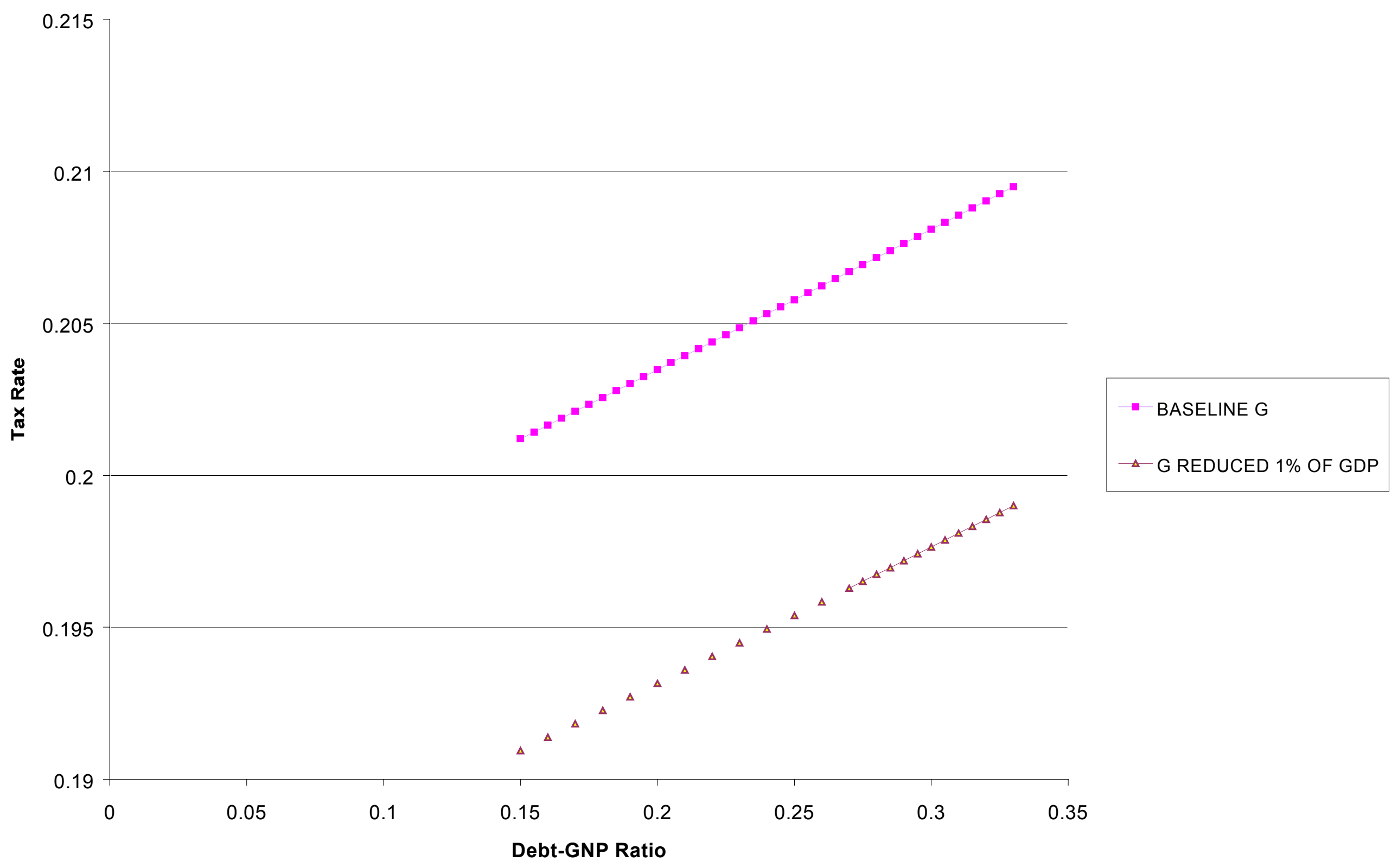


Figure 4: Tax Rate under Standard (BACK) and Constant-Tax (FORWARD) Rules,

Government Spending Decreased by 1\% of GDP Permanently and Unexpectedly in 2010.

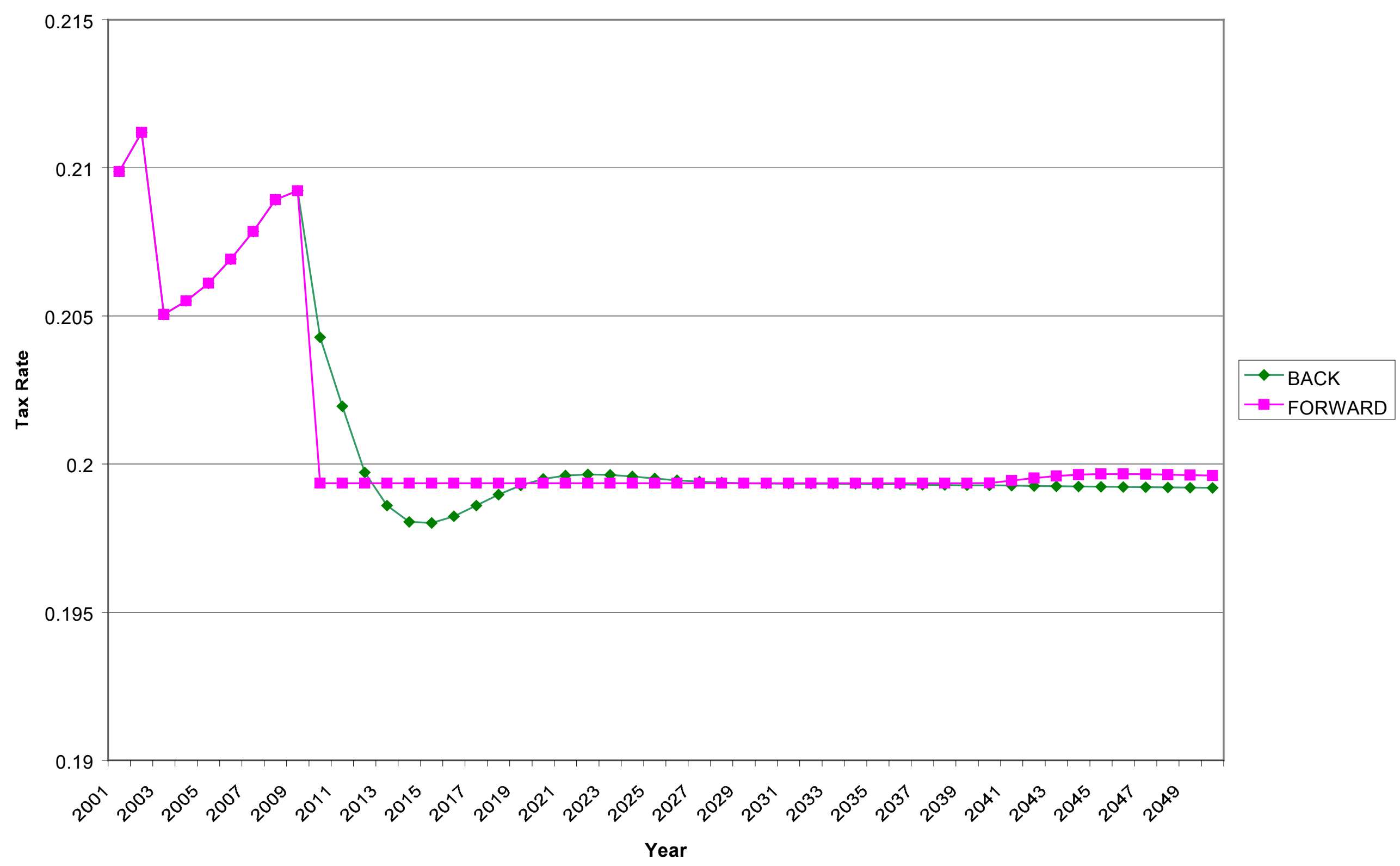


Figure 5: GDP under standard (BACK) and constant-tax (FORWARD) Closure Rules. Government Spending Decreased by 1\% of GDP Permanently and Unexpectedly in 2010.

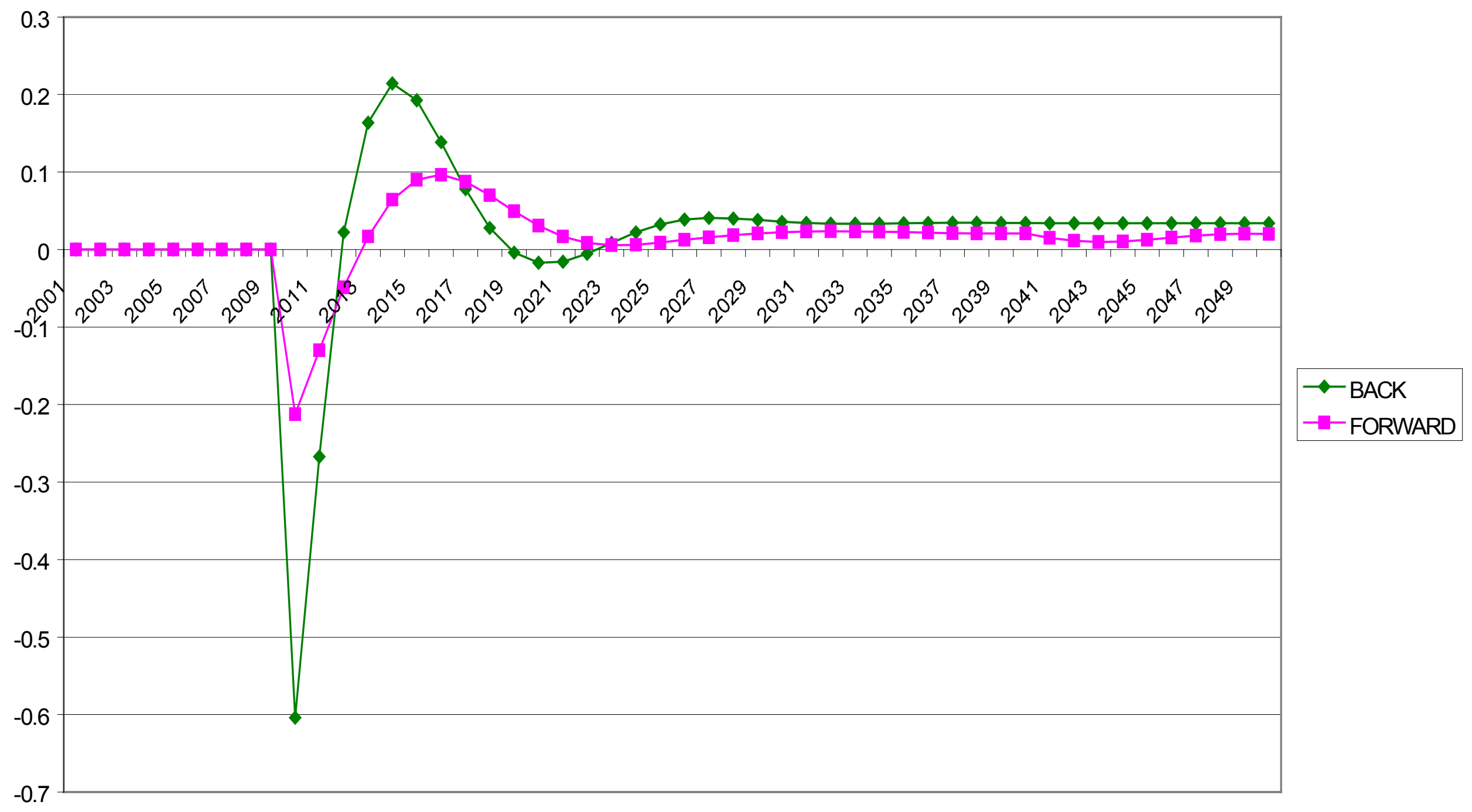


Figure 6: Private Consumption under Standard (BACK) and Constant-Tax (FORWARD) Rules, Government Spending Decreased by 1\% of GDP Permanently and Unexpectedly in 2010.

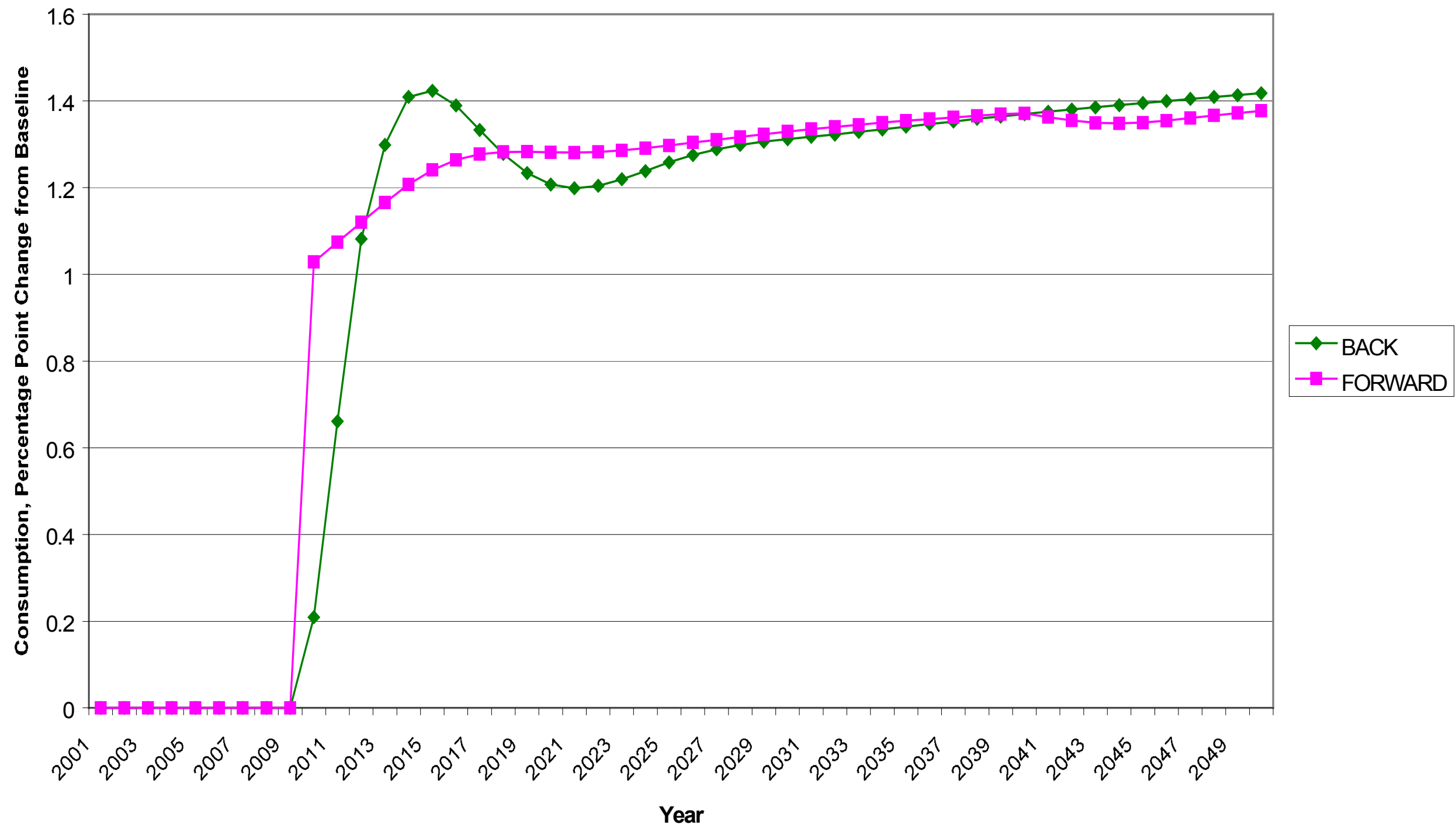


Figure 7: Debt:GNP Ratio under Standard (BACK) and Constant-Tax (FORWARD) Rules,

Government Spending Decreased by 1\% of GDP Permanently and Unexpectedly in 2010.

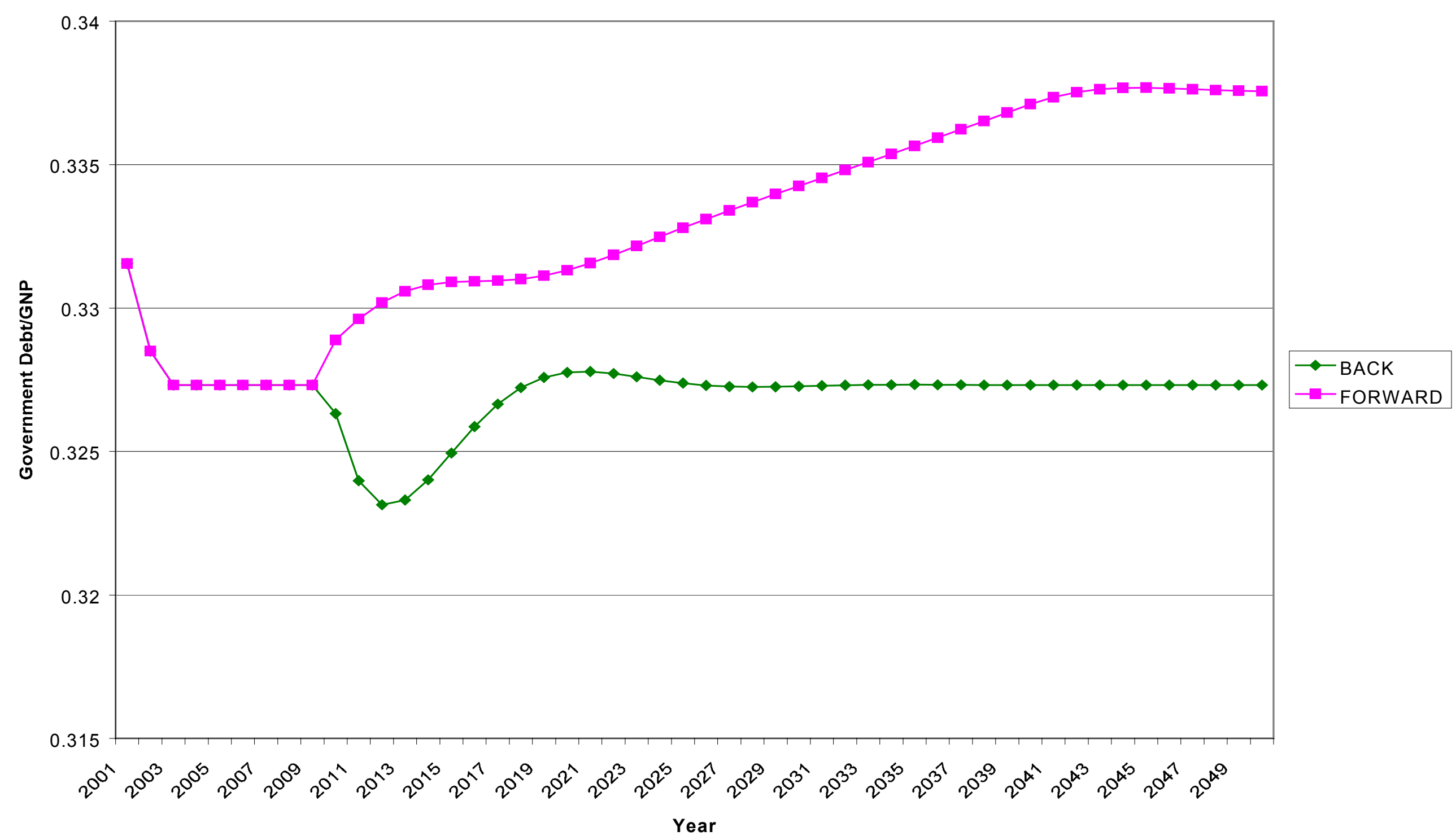


Figure 8: German GDP under Constant-Tax (FORWARD) and Standard (BACK) Fiscal Rules. Here the Constant Tax is Implemented Using $F=20$, rather than $F=30$ as in Figures 3 to 6 .

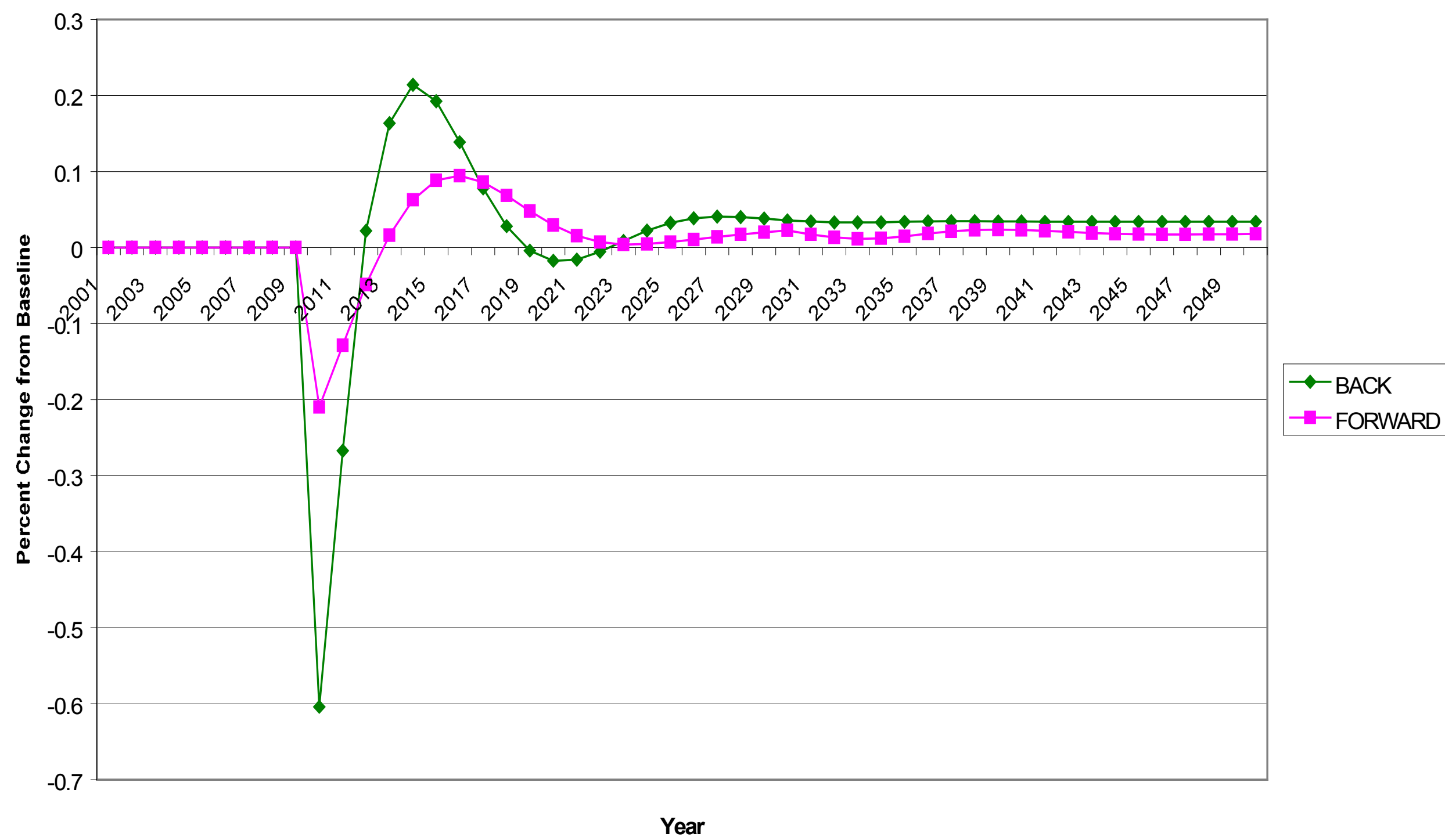


Figure 9: Inflation Rate, Canadian Money Target Permanently Increased 10\% from 2010, under Standard (BACK) and Constant-Tax (FORWARD) Fiscal Rules

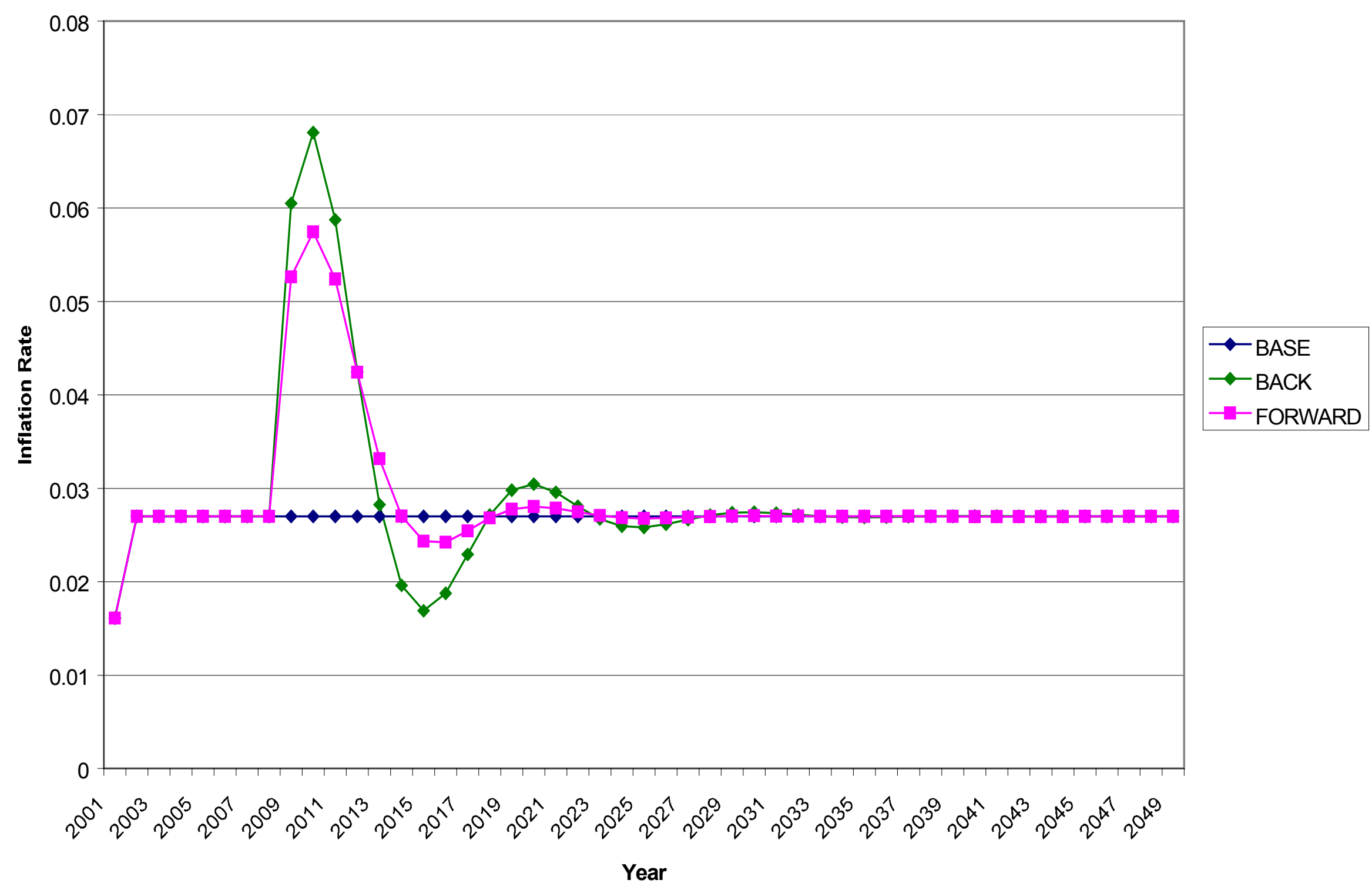


Figure 10: Short Interest Rate, Canadian Money Target Increased 10\% Permanently in 2010, Simulations under Standard ('BACK') and Constant-Tax ('FORWARD') Fiscal Rules

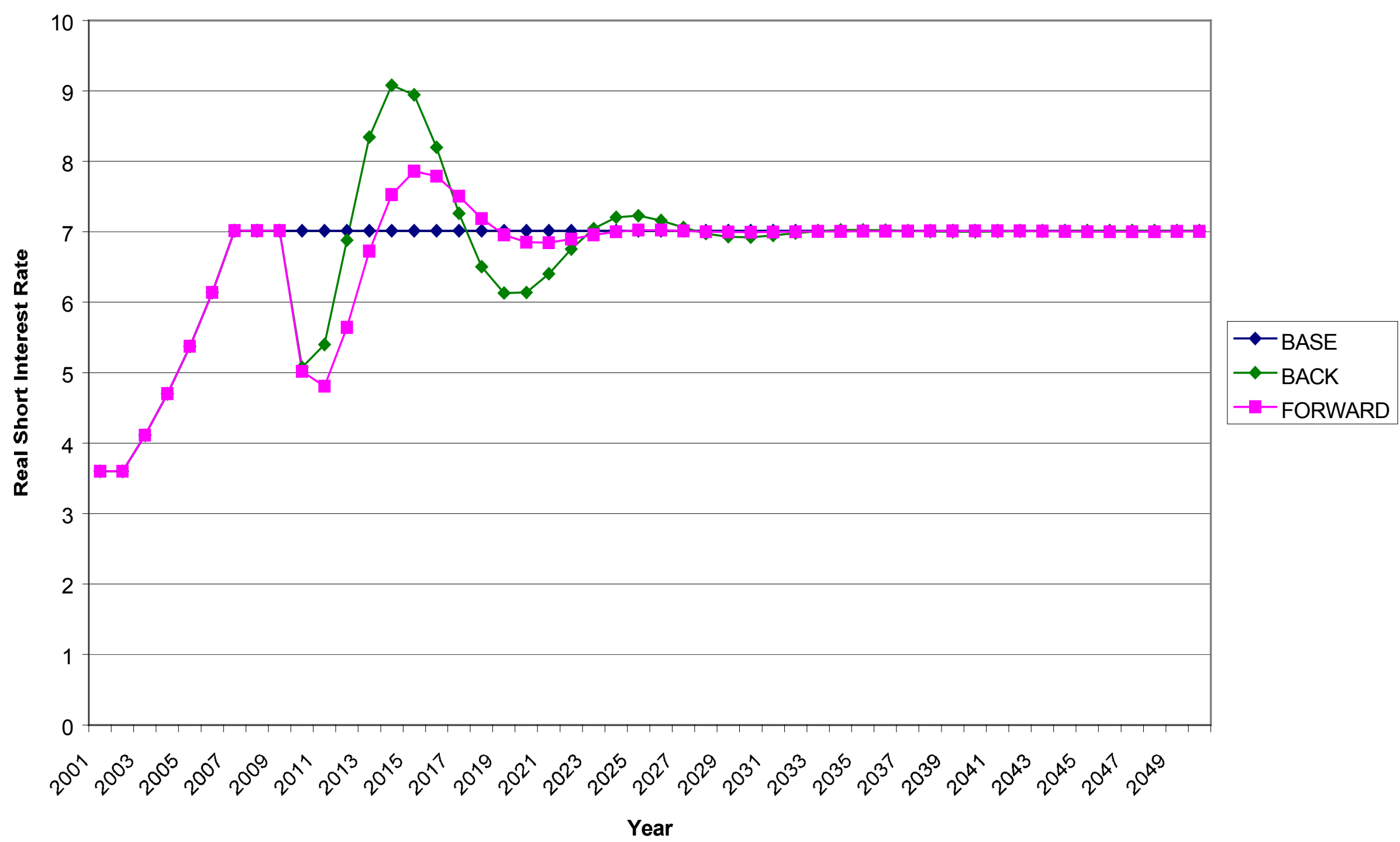


Figure 11: Tax Rates, Canadian Money Supply Target Increased 10\% Permanently in 2010, Under Standard ('BACK') and Constant-Tax ('FORWARD') Fiscal Rules

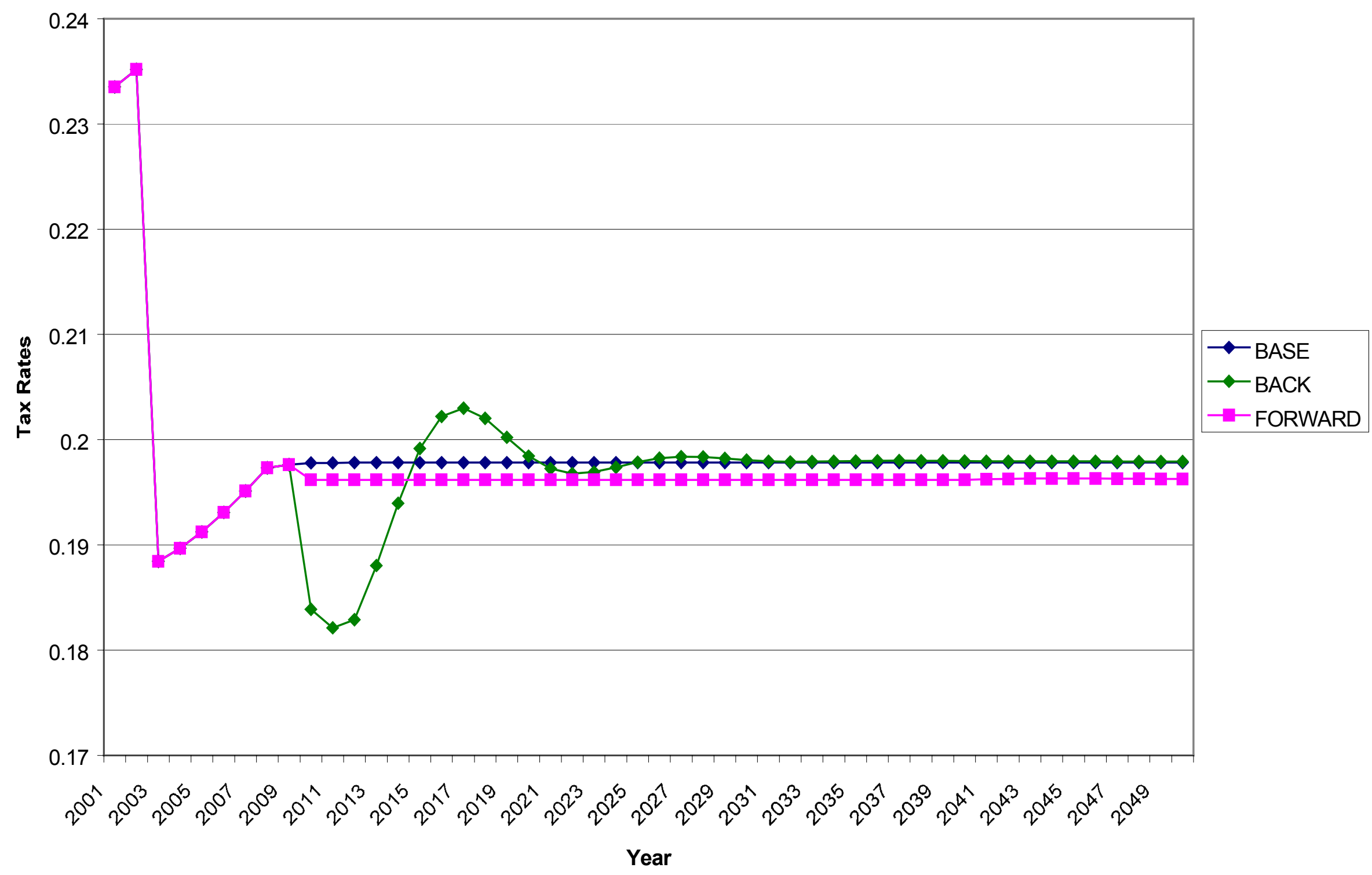


Figure 12: Debt-GNP Ratio, Canadian Money Target Increased 10\% Permanently in 2010, Standard ('BACK') and Constant-Tax ('FORWARD') Fiscal Rules

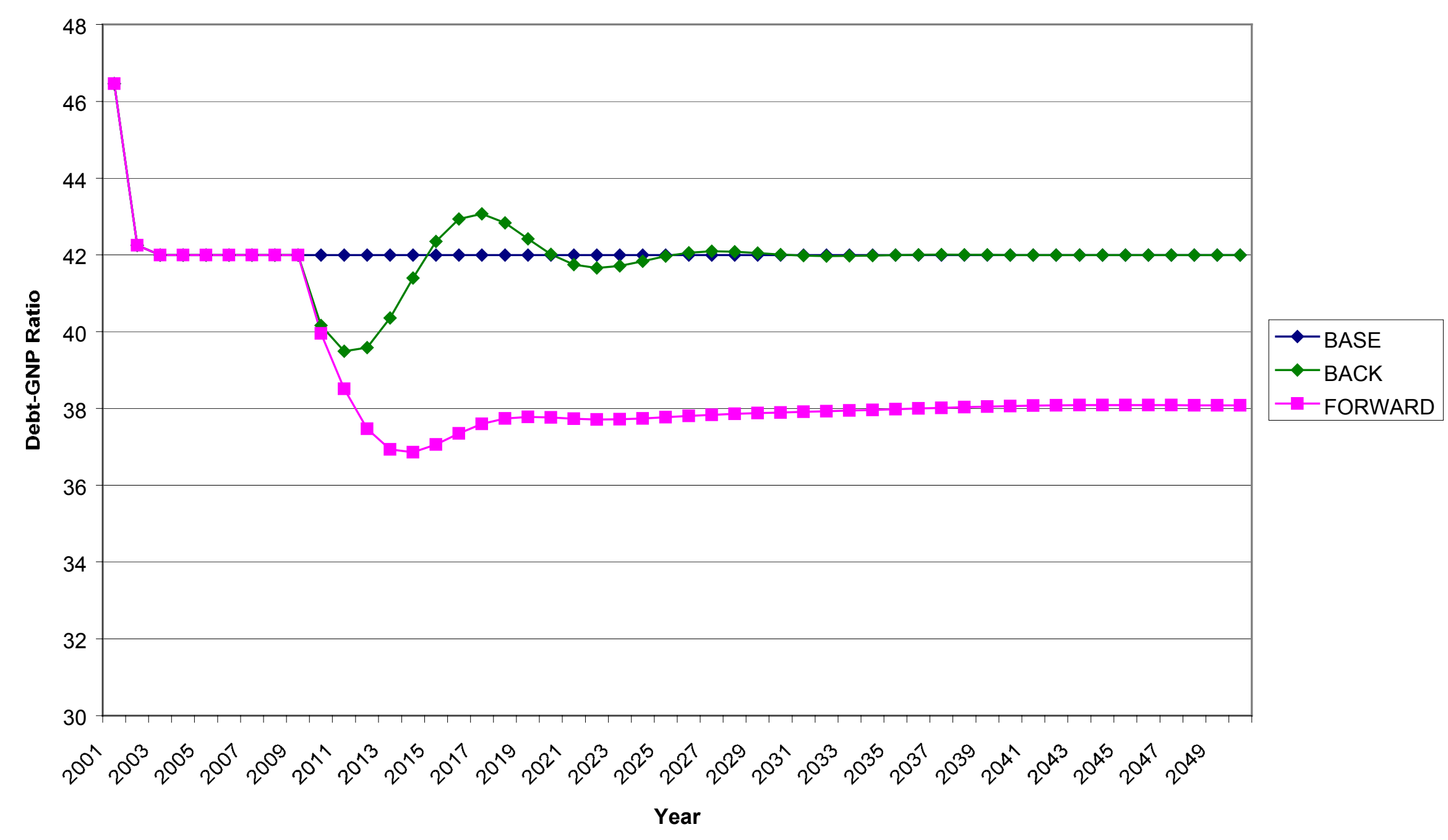


Figure 13: GDP, Canadian Money Supply Target Increased Permanently by $10 \%$ in 2010 , Standard ('BACK') and Constant-Tax ('FORWARD') Fiscal Rules

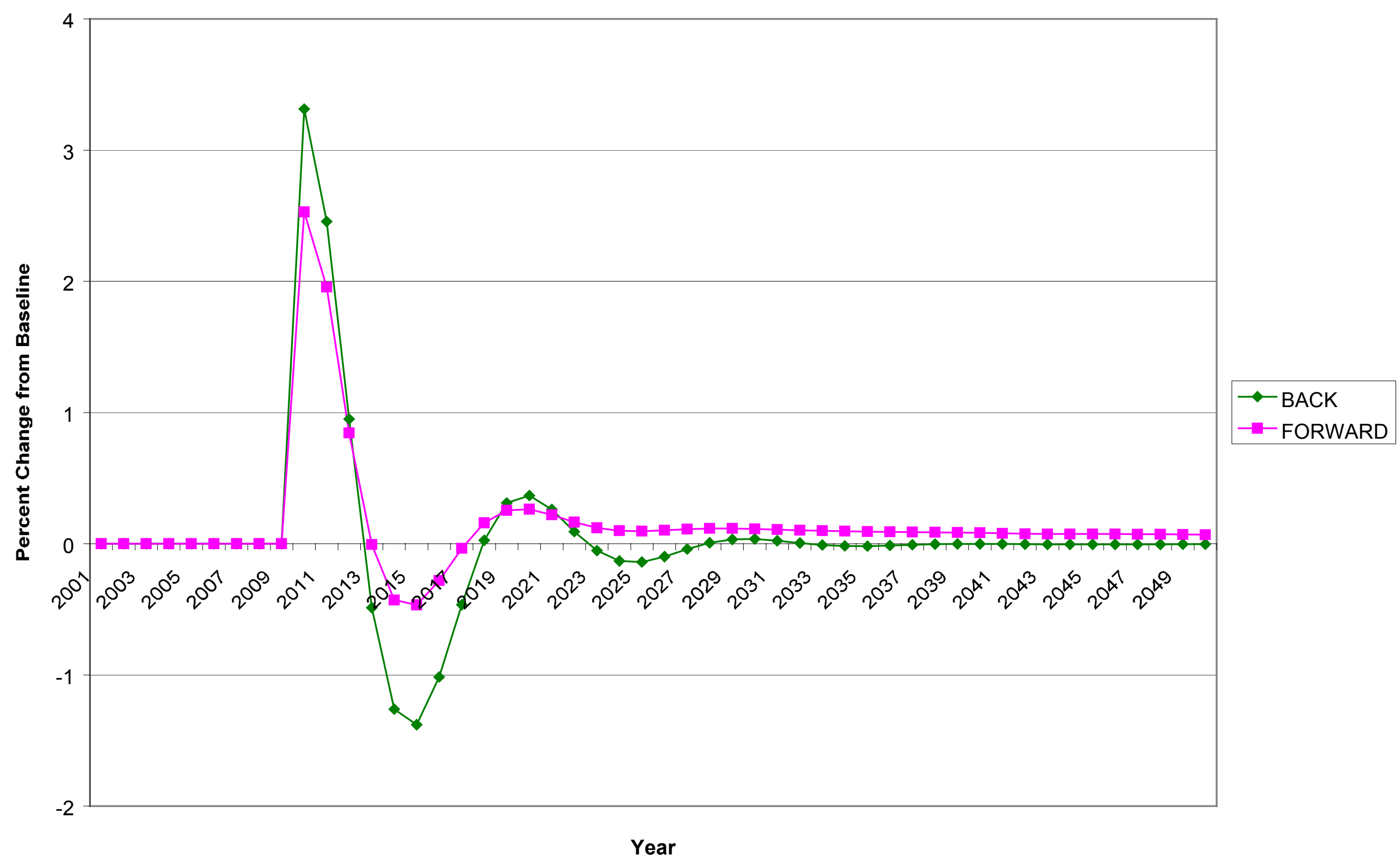


Figure 14: Tax Rate,

Government Consumption Reduced by $1 \%$ Permanently in 2010,

'Sticky-Tax' Fiscal Rules Modelled Using Standard (BACK) and Constant-Tax (FORWARD)

Approaches.

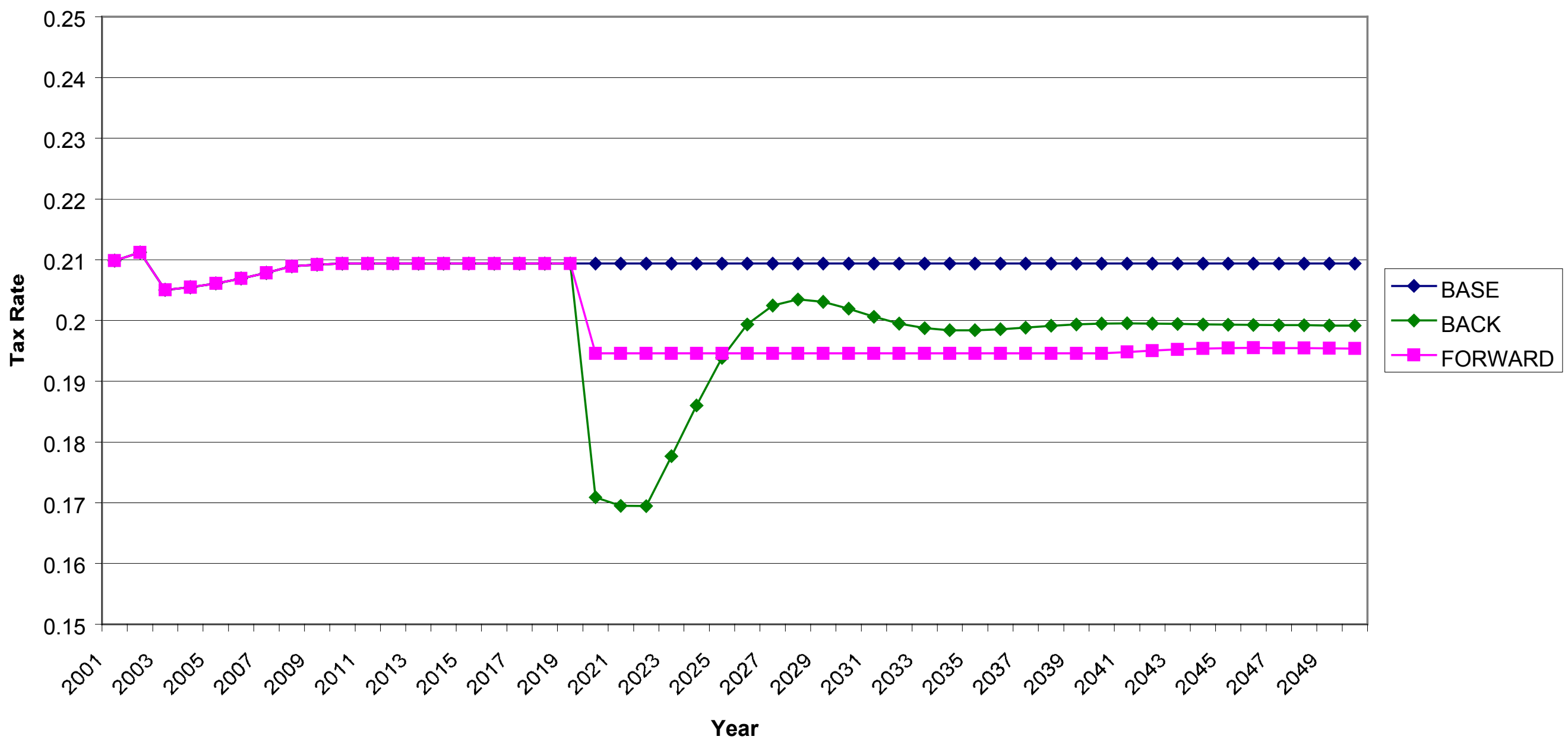


Figure 15: Private Consumption,

Government Consumption Reduced Permanently by $1 \%$ of GDP in 2010, 'Sticky-Tax' Fiscal Rules Modelled Using Standard (BACK) and Constant-Tax (FORWARD) Approaches.

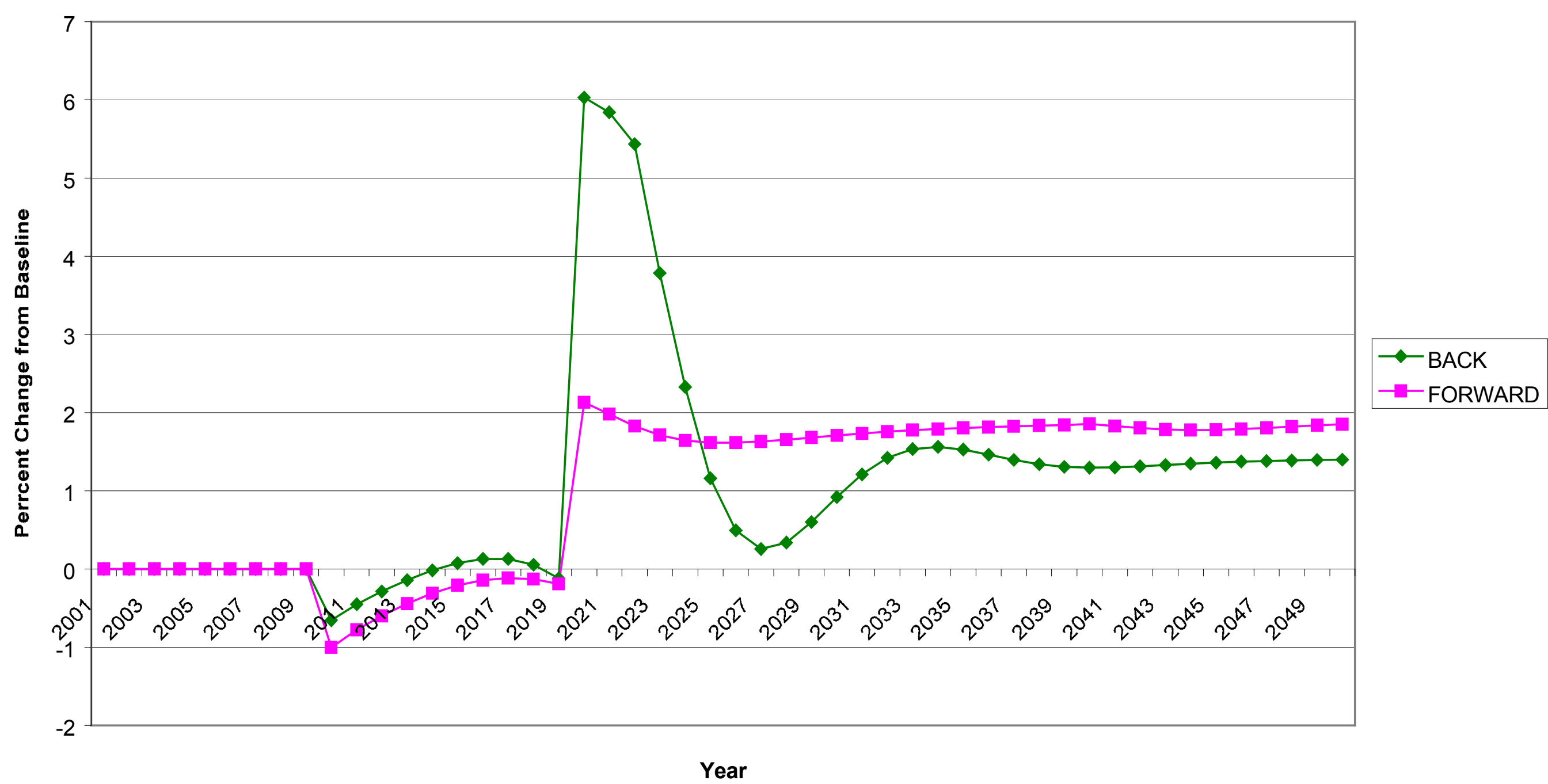


Figure 16: GDP,

Government Consumption Reduced by 1\% of GDP Permanently From 2010, 'Sticky-Tax' Fiscal Rules Modelled Using Standard (BACK) and Constant-Tax (FORWARD) Approaches.

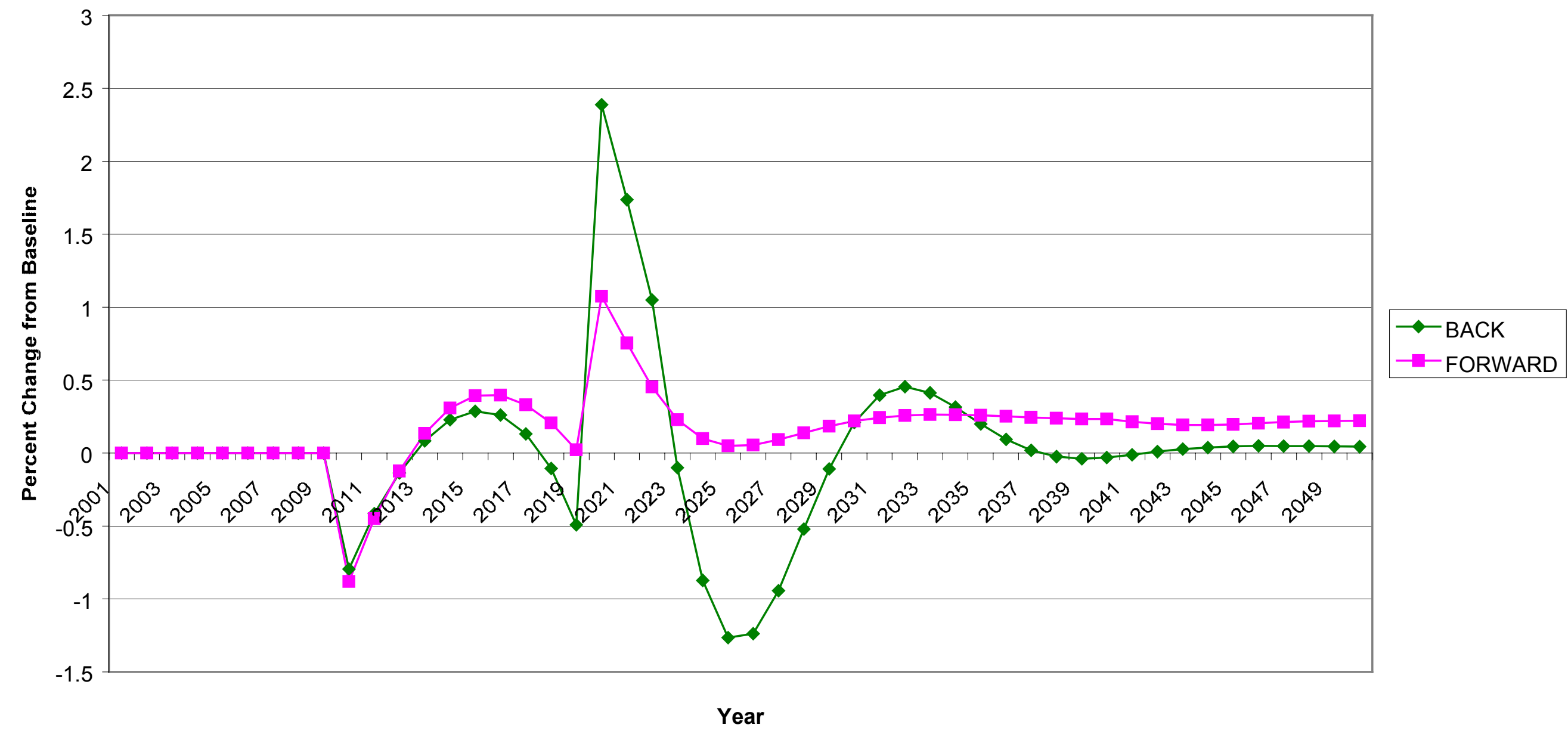


Figure 17: Private Consumption,

Government Consumption Reduced Permanently by $1 \%$ of GDP in 2010, 'Sticky-Tax' Fiscal Rules Modelled Using Standard (BACK) and Constant-Tax (FORWARD) Approaches.

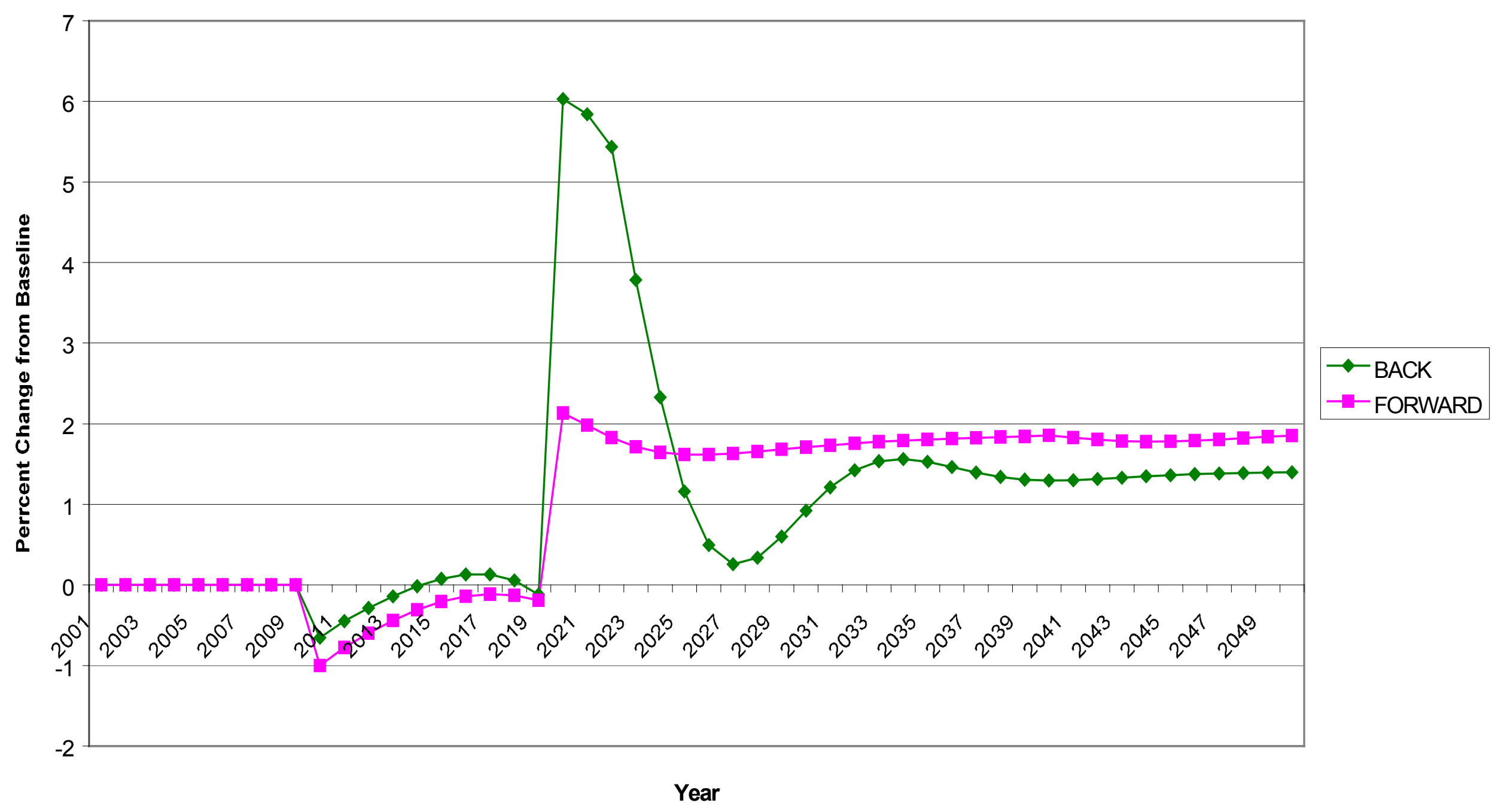

